\title{
Modelo multicritério de apoio à decisão construtivista no processo de avaliação de fornecedores
}

\author{
Leonardo Ensslin ${ }^{\mathrm{a}}$, Sandra Rolim Ensslin ${ }^{\mathrm{b} *}$, Silvano Rochac, \\ Alysson Diego Marafon ${ }^{\mathrm{d}}$, Thalita Assad Medaglia ${ }^{\mathrm{e}}$ \\ aleonardoensslin@gmail.com, UFSC, Brasil \\ b*sensslin@gmail.com, UFSC, Brasil \\ 'silvano.rocha2@hotmail.com, UFSC, Brasil \\ dalyssonmarafon@gmail.com, UFSC, Brasil \\ ethalita.medaglia@engevix.com.br, UFSC, Brasil
}

\begin{abstract}
Resumo
0 presente trabalho tem como objetivo geral avaliar os fornecedores de equipamentos mecânicos de uma empresa de engenharia e, com isso, viabilizar o aumento da competitividade da organização. Para isso, utilizou-se a metodologia multicritério de apoio à decisão construtivista (MCDA-C), a qual compreende as seguintes etapas: i) Estruturação; ii) Avaliação; e iii) Recomendações. A aplicação dessa metodologia permitiu construir conhecimento acerca do contexto abordado considerando, nesse sentido, seus aspectos mais importantes, e suportar a tomada de decisão. A importância deste trabalho alicerça-se na poderosa ferramenta deixada como legado aos envolvidos diretamente no processo (empresa de engenharia e fornecedores); nas melhorias consequentes em toda a cadeia de infraestrutura do Brasil, assim contribuindo para o desenvolvimento nacional; e no enobrecimento e extrapolação da fronteira do conhecimento teórico e prático na grande área de avaliação de desempenho.
\end{abstract}

Palavras-chave

Avaliação de desempenho. Avaliação de fornecedores. Metodologia multicritério de apoio à decisão construtivista (MCDA-C).

\section{Introdução}

Especula-se que, dentro de poucos anos, o Brasil comporá o grupo das cinco maiores economias mundiais, ou seja, o país será detentor de um PIB menor apenas que dos EUA, China, Japão e Alemanha. Trata-se de um mercado emergente, com uma história convincente de crescimento econômico. Segundo o Ministério do Planejamento (BRASIL, 2010a), o PIB do Brasil cresceu 7,5\% em 2010, enquanto dos EUA expandiu apenas 2,9\%. 0 Brasil tem criado empregos a uma taxa de mais de um milhão por ano desde 2005, conforme estatísticas do Ministério do Trabalho (BRASIL, 2010b). De acordo com a Fundação Getúlio Vargas (FGV) (2010), desde esse mesmo ano a média da população de alta renda aumentou 50\%, elevando um adicional de 32 milhões de pessoas com poder de compra para impulsionar o consumo e uma economia mais robusta. Não fortuitamente, o
Brasil foi um dos últimos a sofrer os efeitos da crise econômico-financeira que atingiu o mundo inteiro em 2008, foi um dos primeiros a sair e a mostrar evidentes sinais de crescimento e mantém-se economicamente equilibrado frente às dificuldades mundiais de 2011.

A fim de sustentar o progresso econômico, maiores investimentos em infraestrutura básica são demandados. Uma economia crescente e alta classe de consumo apresentam maior necessidade de energia, telecomunicações, saneamento, habitação e transporte. Nesse contexto encontram-se as empresas de engenharia, que se aproveitam da pujança econômica brasileira para desenvolver obras que envolvem milhões de reais. Exorbitantemente, o governo federal (BRASIL, 2010c) pretende construir, a partir de 2011, 54 hidrelétricas com recursos do Programa de Aceleração do Crescimento 2 (PAC 2), 
um investimento que totalizará $\mathrm{R} \$ 116$ bilhões. Sabe-se que boa parte desse valor será destinada aos equipamentos que compõem as hidrelétricas e que cerca de 60\% deles são mecânicos. A inexistência de modelos científicos de suporte à tomada de decisão durante o processo de compra de tais itens coloca a prova a eficiência de toda a cadeia produtiva, impactando consideravelmente o total investido.

No processo de compra, a seleção de fornecedores vem ganhando cada vez mais importância. 0 aumento no valor dos itens comprados em relação ao total da receita das empresas, a aquisição de produtos de outros países, viabilizada pela globalização a preços competitivos, e a crescente velocidade de mudança de tecnologia, acompanhada por uma redução do ciclo de vida dos produtos, são alguns dos fatores que contribuem para a relevância da seleção de fornecedores. A seleção de fornecedores no processo de compras, no contexto competitivo em que as empresas se encontram, demanda o desenvolvimento de diferenciais para sobrevivência em um mercado em constante mudança (LANGENDYK, 2002).

Revela-se, sob tal conjuntura, a pergunta de pesquisa do presente trabalho: quais os aspectos que devem ser abordados para o processo de avaliação de fornecedores de equipamentos mecânicos de uma empresa de engenharia em um modelo gerencial, que permitam ao decisor (gestor) apreciar aqueles que contribuem com promoção da competitividade da empresa?

Para essa demanda, o presente trabalho tem como objetivo geral viabilizar a avaliação dos fornecedores de equipamentos mecânicos para uma empresa de engenharia, contribuindo para a competitividade da organização, pensando não apenas no seu lucro, mas também nas necessidades de todos os agentes envolvidos (DA ROSA et al., 2011).

Especificamente, busca-se o desenvolvimento de um processo de gestão para seleção de fornecedores que permita:

- Possibilitar a comparação dos diferentes fornecedores;

- Explicitar os atores do contexto e, em particular, o decisor;

- Identificar e disseminar o entendimento do que é importante em um fornecedor;

- Mensurar os aspectos relevantes;

- Integrar níveis táticos e operacionais aos objetivos estratégicos do processo de compras de maneira organizada;

- Diagnosticar a situação de cada fornecedor;

- Ser capaz de influenciar o processo de aperfeiçoamento dos fornecedores;

- Construir conhecimento sobre o contexto; e
- Dar credibilidade, coerência e transparência às decisões, fornecendo qualidade ao processo decisório.

0 atendimento das metas propostas faz-se possível por meio da utilização da metodologia multicritério de apoio à decisão construtivista (MCDA-C) como instrumento de avaliação de desempenho (AD).

0 presente artigo discorre sobre os conceitos envolvidos pela metodologia, ao passo que apresenta um estudo de caso de desenvolvimento de um modelo multicritério para avaliação de fornecedores de equipamentos mecânicos para uma empresa de engenharia a partir da MCDA-C.

A relevância do trabalho alicerça-se: i) no legado deixado aos envolvidos no processo - empresa de engenharia e fornecedores - facilmente percebido no conhecimento gerado sobre o contexto e no processo estruturado construído para dar suporte ao aperfeiçoamento desse contexto; ii) no aprendizado dos estudantes de mestrado, facilitadores do processo; e iii) nas melhorias consequentes em toda a cadeia de investimentos em infraestrutura no Brasil, contribuindo dessa maneira para o desenvolvimento nacional.

Este trabalho apresenta, após esta seção introdutória, o constructo teórico, que explana a respeito da pesquisa operacional e da MCDA-C, além da avaliação de fornecedores de acordo com a definição de avaliação de desempenho adotada pelos autores. Em seguida, tem-se a metodologia, que expõe o enquadramento metodológico de pesquisa e a construção do modelo multicritério, abrangendo conceitos de construção do modelo. Na sequência, o estudo de caso é dividido em três partes: estruturação, avaliação e recomendações. Por último, encontra-se a seção com as considerações finais, espaço no qual são expostas as conclusões da pesquisa.

\section{Constructo teórico}

Para a explicitação do modelo teórico, subdivide-se a seção descrevendo-se a metodologia multicritério de apoio à decisão - construtivista (MCDA-C) a partir da pesquisa operacional (PO) e, sequencialmente, a avaliação de fornecedores (AF) baseada na avaliação de desempenho (AD).

\subsection{A pesquisa operacional e a MCDA-C}

A origem da MCDA dá-se na pesquisa operacional, ciência esta desenvolvida no período da Segunda Guerra Mundial para lidar com a tomada de decisão, por interesse de pesquisadores matemáticos e estatísticos, para a estratégia militar (LYRIO et al., 2007). Desde o sucesso da PO, naquela época, estudos foram desenvolvidos para adequá-la ao 
ambiente decisório organizacional até o momento em que se fez necessário classificá-la em dois grandes tipos de pesquisas operacionais: a PO Hard, que procura desenvolver modelos matemáticos a fim de atingir a solução ótima; e a PO Soft, que se volta ao estudo da estruturação dos contextos decisórios, propondo-se a servir como ferramenta de avaliação e apoio à decisão (ENSSLIN et al., 2010a; FRANCO; MONTIBELLER, 2010).

Examinando amplamente a grande área da Teoria da Decisão sob as três visões do conhecimento, tem-se: i) a visão descritivista, que é a observação do mundo como este se apresenta e não emite julgamento sobre a realidade descrita; ii) a visão normativa (ou normativista), a qual está associada à visão do mundo através de processos idealizados, esta visão defende o uso de fórmulas matemáticas que serão manipuladas pelo decisor; e iii) a visão construtivista, que consiste em construir modelos através do processo decisório. Nessa última, a estruturação de um modelo avança de forma interativa e de modo coerente com os objetivos e valores do decisor (VINCKE, 1989; ENSSLIN et al., 2010b).

0 presente estudo posiciona-se de maneira construtivista. Em termos teóricos, a visão adotada neste trabalho utiliza uma lógica de pesquisa construtivista mista (indutiva e dedutiva), enquanto a lógica das demais visões é racionalista dedutiva (ROY, 1993). Isso significa que a visão construtivista da Teoria da Decisão se fundamenta no reconhecimento da necessidade de uma etapa de estruturação, embora, na construção de modelos de apoio à decisão, capaz de desenvolver, no decisor, um corpo de conhecimentos coerente que lhe permita a compreensão das consequências de suas decisões nos aspectos que ele (decisor) julga importantes, sem impor os racionalismos da objetividade, para, então, avaliar esses aspectos e recomendar melhorias (SKINNER, 1986; KEENEY, 1992; ROY, 1993, 1994, 2005; LANDRY, 1995; ROY; VANDERPOOTEN, 1995; ZIMMERMANN, 2000; ENSSLIN et al., 2010a).

Completa-se, então, a MCDA com as convicções básicas da Escola Francesa (ROY, 1996): i) onipresença da subjetividade no processo decisório; ii) paradigma da aprendizagem pela participação; iii) convicção do construtivismo; iv) reconhecimento das limitações do ótimo matemático e utilização de uma abordagem que não parte de quaisquer pré-condições, mas procura construir um modelo de elementos-chave que capacitam os atores a evoluir no processo decisório como resultado dos seus próprios objetivos, convicções e sistemas de valores. Dessa maneira, permite-se chamá-la metodologia multicritério de apoio à decisão - construtivista. Roy (1993) e Landry (1995) destacam a importância da visão construtivista no processo decisório, pois esta busca desenvolver o conhecimento por meio de um processo metodológico e científico.

Logo, na PO Soft, aplica-se o paradigma construtivista, que se baseia na MCDA-C, quando se propõe construir conhecimento sobre um determinado contexto decisório, fundamentado nos valores dos atores envolvidos (BORTOLUZZl et al., 2010, 2011; DELLA BRUNA JUNIOR et al., 2011; GRZEBIELUCKAS, 2011).

\subsection{A avaliação de desempenho e a avaliação de fornecedores}

Para Ensslin et al. (2010b), avaliação de desempenho envolve instrumentos de gestão utilizados para construir, fixar e disseminar conhecimentos. Ensslin et al. (2010a) defendem, ainda, que a AD é a base para a tomada de decisão sobre qualquer situação que envolva escolha. No contexto em questão, a tomada de decisão refere-se a um fornecedor, como, por exemplo, sua escolha.

Pode-se dizer que a função compras tem o objetivo amplo de conseguir tudo ao mesmo tempo: qualidade, quantidade, prazo de entrega e preço. Uma vez sabido o que comprar, a decisão mais importante refere-se ao fornecedor certo. A única afirmação que se pode fazer de antemão é que se busca um fornecedor que venha a contribuir para a competitividade da organização. Segundo Liu, Ding e Lall (2000), para que a etapa de seleção de fornecedores seja eficaz, originando assim uma parceria de sucesso entre comprador e fornecedor, faz-se necessário determinar os critérios de seleção a serem considerados em cada processo, pois são esses que vão determinar quais pontos devem ser confrontados entre os fornecedores interessados na parceria ofertada. Conquanto exista uma diferença de critérios de seleção a serem considerados em cada atividade, é necessário que as empresas se baseiem em critérios corporativos válidos para todas as atividades, de modo a criar uma identidade junto ao mercado de fornecedores e tornar claras suas prioridades e exigências.

Portanto considera-se sensato e inteligente avaliar o desempenho de um fornecedor a fim de realizar um processo de seleção eficaz.

\section{Metodologia de pesquisa}

0 enquadramento metodológico da pesquisa deu-se a partir da estrutura apresentada na Figura 1.

Classifica-se como exploratória a natureza do objetivo, uma vez que se buscou aprofundar o nível de conhecimento a respeito de um contexto 


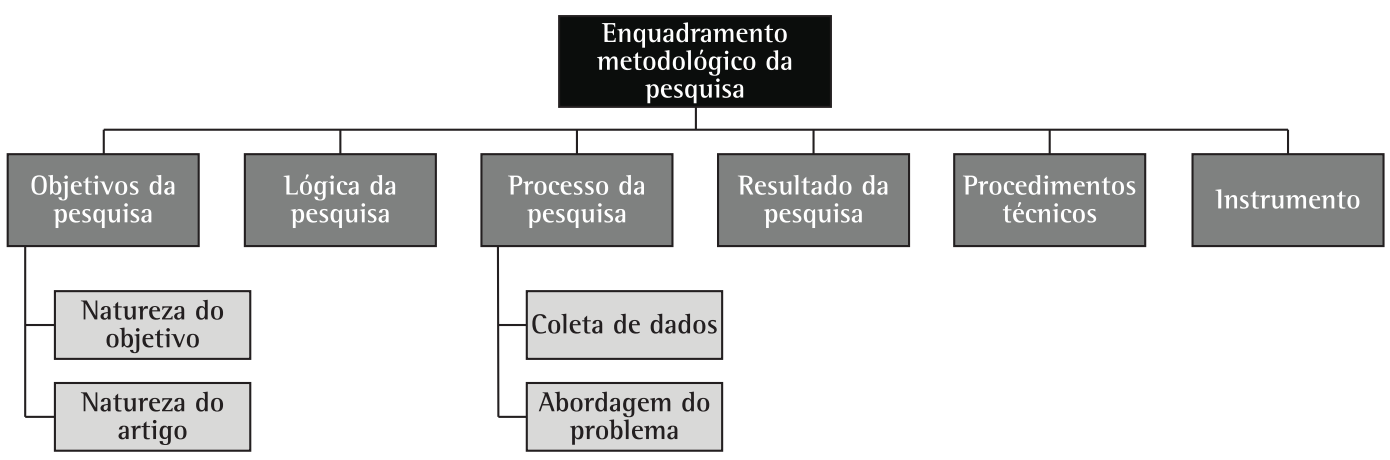

Figura 1. Framework do enquadramento metodológico da pesquisa. Fonte: Adaptado de Tasca et al. (2010).

determinado. Para Gil (1999), isso caracteriza-se pelo aprofundamento sobre o tema em questão, a fim de torná-lo mais explícito, a partir da interação entre os decisores e os facilitadores. A natureza do artigo revela um estudo prático, uma vez que se baseia em um estudo de caso, o qual permite uma investigação que preserva as características da organização em funcionamento (YIN, 2005).

Para Tasca et al. (2010), o processo utilizado pela MCDA-C é híbrido quanto à lógica da pesquisa, ou seja, indutivo e dedutivo. Indutivo pois o resultado da pesquisa não era previsível e a construção do modelo foi possibilitada a partir das percepções dos atores envolvidos. Dedutivo pois, na fase de avaliação do modelo desenvolvido, existe uma resposta para sua validação de pesquisa e pretende confirmá-la.

Quanto ao processo de pesquisa, a coleta de dados ocorreu de maneira primária, através de visitas e entrevistas, e secundária, pela investigação de documentos do setor de suprimentos da empresa de engenharia. A abordagem do problema classifica-se como qualiquantitativa. É qualitativa quando decide examinar situações complexas e estritamente particulares em que a subjetividade é mais presente e se procura entender atividades sociais e humanas, como assinala Richardson (2008). Para o mesmo autor, é quantitativo quando se utiliza de um ferramental estatístico como, por exemplo, na fase de avaliação, para transformação das escalas ordinais em escalas cardinais e para cálculo da avaliação global.

A classificação quanto ao resultado da pesquisa é aplicada pois, para Gil (1999), assim são aquelas que desenvolvem um modelo capaz de ser usado na prática.

Os procedimentos técnicos enquadram esta pesquisa como um estudo de caso, visto que foi construído um modelo para avaliar o desempenho dos fornecedores de uma empresa específica.

0 instrumento de intervenção é a metodologia já citada, MCDA-C. Autores como Skinner (1986), Roy
(1993, 2005), Landry (1995), Bana e Costa et al. (1999) e Zimmermann (2000) alertam para a necessidade de se considerar os valores individuais dos decisores ao se desenvolver um modelo para avaliar o desempenho de sistemas organizacionais, como no caso de um fornecedor, em detrimento das metodologias que adotam valores e preferências coletivas ou determinadas via métodos estatísticos, ou mesmo utilizadas com sucesso no passado. Diante disso, para a estruturação do modelo de avaliação de desempenho, avaliação do contexto e recomendações considera-se a MCDA-C o instrumento adequado.

As principais vantagens provenientes da utilização da MCDA-C são: i) possibilidade de abordar informações qualitativas e quantitativas; ii) possibilidade de capturar e apresentar, de maneira explícita, os objetivos e valores dos decisores; iii) possibilidade de permitir aos decisores refletir sobre seus objetivos, prioridades e preferências; e, (iv) possibilidade de desenvolver um conjunto de condições e meios para informar as decisões em função do que o decisor achar mais adequado (LACERDA; ENSSLIN; ENSSLIN, 2010, 2011a, b; ZAMCOPÉ et al., 2010). Por fim, em situações práticas do estudo, permite, por exemplo, a seleção eficaz de um fornecedor e, até mesmo, a possibilidade de influenciar melhorias em aspectos importantes nos fornecedores, tornando-os mais competitivos para suprir a empresa de engenharia em questão.

\section{Construção do modelo multicritério}

A seleção da metodologia MCDA-C para auxiliar no processo de construção do modelo para seleção de fornecedores deve-se ao fato de ela partir do princípio de que o gerenciamento é um processo contínuo, materializado por meio de decisões para a implementação de ações de melhoria, além de ser um processo social que envolve indivíduos, valores, percepções e relações de poder entre eles (ENSSLIN; MONTIBELLER; NORONHA, 2001). 
Em situações complexas, como a do presente estudo, que envolvem inúmeros atores e múltiplos critérios nem sempre conhecidos em sua totalidade, metodologias do tipo multicritério emergem, reconhecendo, sobretudo, os limites da objetividade preconizada pela visão cartesiana (ROY; VANDERPOOTEN, 1996). A Figura 2 representa todas as etapas abordadas pela MCDA-C em suas três fases.

\subsection{Estruturação do modelo}

Reconhecidamente, a estruturação é a parte mais importante da metodologia por ser seu grande diferencial e demostrar o contexto no qual o problema se encontra inserido, segundo a percepção do decisor em um primeiro momento, e por, em seguida, expor a ampliação do conhecimento e de seus critérios. Para tanto são definidos os atores do contexto, o rótulo, que expressa o objetivo do modelo e a identificação, organização e mensuração dos aspectos críticos que, na visão do decisor, melhor expressem seus valores e preferências.

\subsubsection{Contextualização, atores, rótulo e sumário}

0 presente estudo foi desenvolvido em uma empresa brasileira de engenharia com sede em São Paulo e que tem a sua filial de Florianópolis à frente de usinas hidrelétricas no modelo empreitadas integrais, EPC (engineering, procurement and construction). Nessa modalidade, a empresa torna-se responsável por toda a obra e mostra-se apta a realizar desde a engenharia básica e detalhamento do projeto até a compra de equipamentos e materiais, gerenciamento da construção civil, montagem, pré-operação e operação propriamente dita. Ela é capaz de gerenciar todas as fases da obra.

Dentre as atividades desenvolvidas por uma "epecista", a compra de equipamentos, sob a responsabilidade da área de suprimentos, merece especial atenção por se mostrar uma das partes mais rentáveis do negócio. Ademais, tal área, nas organizações, tem como responsabilidade selecionar fornecedores e realizar a aquisição de produtos e matérias-primas a serem utilizados pelas empresas, portanto é a área que define o cerne da qualidade e a competitividade de preço. logo, é um ponto estratégico para a alocação de esforços.

A principal forma de alocar tais esforços é por meio da definição dos critérios que determinam o que é relevante para a empresa na hora de escolher um fornecedor. Nesse contexto, pensando em um sistema de transformação, com entradas e saídas, pode-se dizer que os inputs do setor de compras de uma empresa são as necessidades da empresa, os fornecedores existentes, os fornecedores a serem desenvolvidos e a busca por capital. Como outputs, têm-se matérias-primas, produtos acabados, qualidade, preço, condições de entrega e prazo (TRINDADE et al., 2007). Usualmente, as organizações centram-se nas saídas preço e qualidade, mas, na prática, o que elas buscam é um conjunto de aspectos mais completo. Cabe ao setor de compras a obtenção de tudo aquilo que desejam.
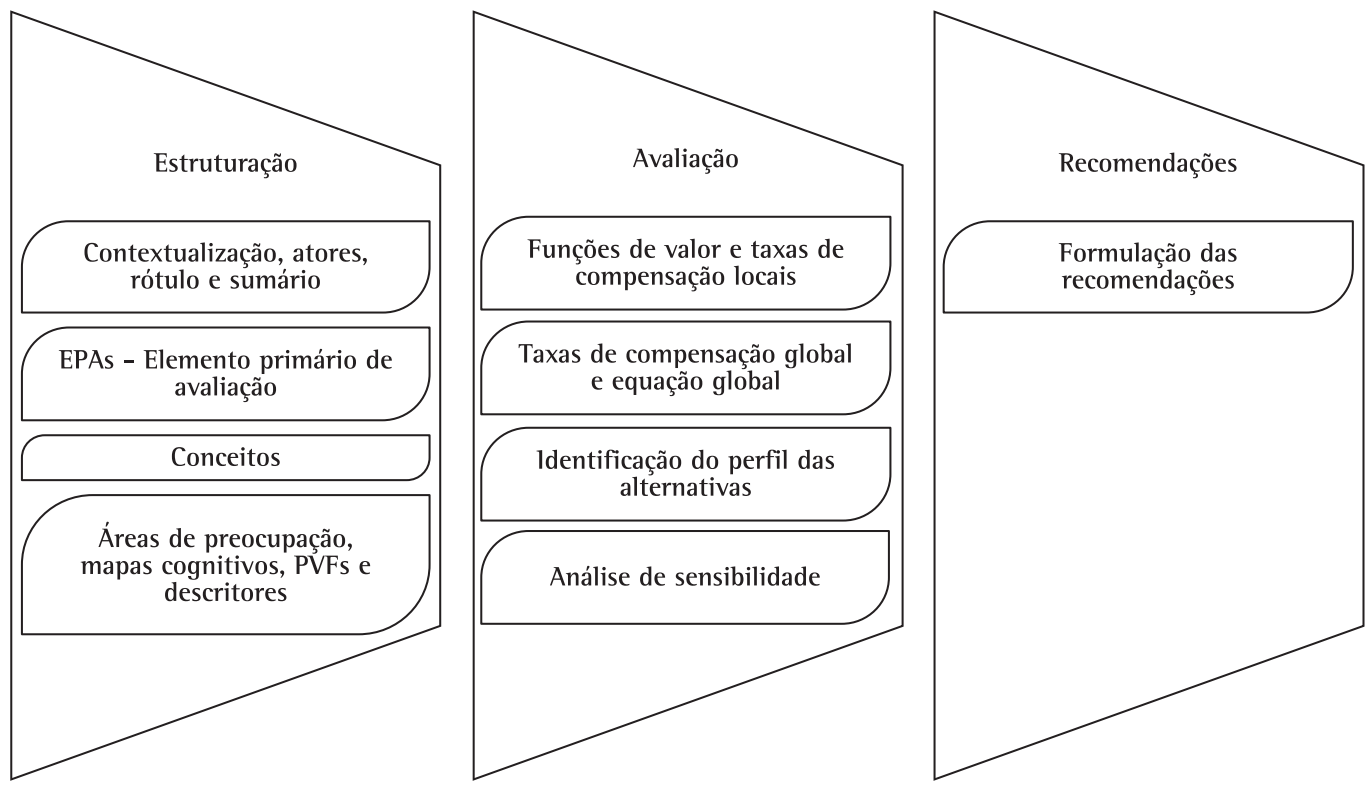

Figura 2. Fases do processo MCDA-C. Fonte: adaptado de Ensslin et al. (2010b). 
Nesse contexto, a área de suprimentos da empresa em estudo é responsável pela aquisição de todos os equipamentos e miscelâneas das usinas, sendo os equipamentos divididos em: equipamentos de geração - turbina e gerador, os quais representam aproximadamente $60 \%$ do valor de aquisição, equipamentos mecânicos principais - levantamento e hidromecânicos, os quais contribuem com 25\% do valor, e equipamentos elétricos, sistemas mecânicos e elétricos auxiliares e equipamentos de pátio, que somados representam 10\% das aquisições. Os $5 \%$ restantes são destinados às miscelâneas. Por questões estratégicas, os fornecedores de turbinas

Quadro 1. Atores do contexto.

\begin{tabular}{cll} 
& \multicolumn{1}{c}{ Decisores } & \multicolumn{1}{c}{$\begin{array}{c}\text { Coordenador da área de } \\
\text { suprimentos } \\
\text { Jobleader }\end{array}$} \\
\cline { 2 - 3 } Stakeholders & & $\begin{array}{l}\text { Colaboradores da área de } \\
\text { suprimento } \\
\text { Colaboradores da área de } \\
\text { engenharia } \\
\text { Superiores } \\
\text { Clientes }\end{array}$ \\
\hline Facilitadores & \multicolumn{1}{|c|}{ Autores do presente trabalho } \\
\hline Agidos & $\begin{array}{l}\text { Fornecedores } \\
\text { Demais colaboradores da empresa } \\
\text { lnvestidores }\end{array}$ \\
\hline
\end{tabular}

Fonte: dados da pesquisa.

Quadro 2. Elementos primários de avaliação.

\begin{tabular}{cc}
\hline Conceito & Descrição \\
\hline 1 & Adaptabilidade \\
2 & Adequação \\
3 & Corpo de engenharia \\
4 & Desenhos \\
5 & Inovação \\
6 & Instrução técnica \\
7 & Terceirizado \\
8 & Ambientalismo \\
9 & Confiabilidade na proposta \\
10 & Garantias \\
\hline
\end{tabular}

Fonte: dados da pesquisa. e geradores são parceiros determinados pela alta diretoria da empresa e, na grande maioria das vezes, são determinados antes do fechamento do contrato com o cliente. Dessa forma, o presente trabalho propõe-se a avaliar e selecionar fornecedores de equipamentos mecânicos principais devido à alta representatividade dos mesmos no montante de custos da área de suprimentos.

A partir desta contextualização, são definidos os atores envolvidos, conforme Quadro 1.

Após a definição dos envolvidos, passou-se para a construção do rótulo, que foi determinado como modelo multicritério para avaliação de fornecedores de equipamentos mecânicos para uma empresa de engenharia.

\subsubsection{Elementos primários de avaliação e conceitos}

Ainda na fase de estruturação do modelo, entrevistas abertas foram feitas com os decisores de forma a levantar informações relativas a valores, expectativas e vontades pessoais. As entrevistas foram gravadas, para que pudessem ser mais bem aproveitadas na coleta e análise de dados. Dessas entrevistas, foram retirados os elementos primários de avaliação ou simplesmente EPAs, que são as características ou propriedades do contexto que o decisor julga que impactam em seus valores. Esses elementos são constituídos de objetivos, metas, valores dos decisores, além de ações, opções e alternativas (BANA E COSTA et al., 1999). Nesse momento, o que se busca é o maior número possível de EPAs. A análise das entrevistas permitiu aos autores chegar em 94 EPAs, cujos 10 primeiros podem ser vistos no Quadro 2.

Uma vez elencados os EPAs parte-se para a descrição dos conceitos. Cada EPA pode dar origem a um ou mais conceitos (ENSSLIN; MONTIBELLER; NORONHA, 2001). 0 conceito expressa a direção de preferência associada ao EPA acompanhado

Quadro 3. Conceito dos EPAs.

\begin{tabular}{|c|c|}
\hline Conceito & Descrição \\
\hline 1 & Possuir adaptabilidade de requisitos incoerentes com os desejados primeiramente... Ter que substituir o fornecedor \\
\hline 2 & $\begin{array}{l}\text { Possuir capacidade adequada para produzir equipamentos complexos... Buscar fornecedores alternativos para os } \\
\text { equipamentos complexos }\end{array}$ \\
\hline 3 & Possuir corpo de engenharia de desenvolvimento de projetos de produtos... Aumentar o risco no repasse de informação \\
\hline 4 & Garantir precisão dos desenhos... Ter alterações constantes ou excessivas \\
\hline 5 & Ser fornecedor inovador em tecnologia... Não parecer atraente às vistas da empresa \\
\hline 6 & Garantir disponibilidade de ETs para propostas... Elaborar propostas incoerentes \\
\hline 7 & Ser uma empresa terceirizada de outras maiores reconhecidas... Pagar caro por equipamentos "de marca" \\
\hline 8 & Possuir responsabilidade ambiental... Prejudicar a imagem da obra e da empresa \\
\hline 9 & Manter confiabilidade... Perder editais ou fornecedor para concorrentes \\
\hline 10 & Oferecer garantias satisfatórias... Ter custos inesperados com reparos \\
\hline
\end{tabular}


da motivação para sua existência. Cada conceito é contra-atacado por seu polo oposto psicológico, o qual explicita o grau mínimo de aceitação do objetivo em questão. No Quadro 3 são indicados os primeiros 10 conceitos, com seus respectivos polos opostos psicológicos.

No estudo de caso em questão, 108 conceitos foram criados. Os conceitos que, segundo a visão do decisor, apresentam preocupação estratégica semelhante podem ser agrupados em áreas de preocupação.

\subsection{3. Áreas de preocupação, mapas cognitivos e pontos de vista fundamentais (PVFS)}

O agrupamento dos conceitos em áreas de preocupação tem como função reunir os conceitos criados tendo em conta os valores do decisor e o contexto. Cada área de preocupação recebe um nome que tem a responsabilidade de refletir da melhor forma possível a preocupação principal do decisor. Vale ressaltar, entretanto, que com o melhor entendimento do contexto e aprofundamento do conhecimento essas áreas de preocupação podem e devem ter seu nome alterado, expressando, cada vez mais, a realidade do problema em questão.

A Figura 3 exibe áreas de preocupação e respectivos conceitos.

Com os conceitos que apresentam preocupação semelhante agrupados torna-se possível expandir ainda mais o conhecimento por meio da criação dos mapas meio-fim, também, denominados mapas cognitivos. Autores como Montibeller, Shaw e Westcombe (2006), Montibeller et al. (2008) e Montibeller e Belton (2009) definem mapa cognitivo como uma hierarquia de conceitos, relacionados por ligações de influência entre meios e fins. Essa ligação de influência é construída por meio de duas perguntas que devem ser feitas ao decisor quando da análise de cada conceito. Essas perguntas são: Por que este conceito é importante? E como se pode obter tal conceito?

Durante a criação dos mapas é possível e muito provável que outros conceitos sejam criados como forma de resposta às perguntas. Da mesma forma, pode-se notar que alguns conceitos não se encontram na área de preocupação mais adequada ou mesmo não representam uma preocupação pertinente ao modelo. No primeiro caso, tais conceitos podem ser incluídos no modelo; e aqueles do segundo caso podem ser descartados. Esse processo faz parte da construção do conhecimento.

Com o intuito de facilitar a análise dos mapas, esses são divididos em clusters, que, por sua vez, podem ser divididos em subclusters. Cluster é um conjunto de nós relacionados de forma muito forte, que pode ser analisado com um mapa independente de complexidade reduzida. Para cada cluster associa-se um nome que deve refletir o foco de interesse do decisor. A Figura 4 mostra a área de preocupação comprometimento, com seu mapa cognitivo e clusters.

Neste ponto é possível observar a inclusão dos conceitos em verde, os quais não haviam sido

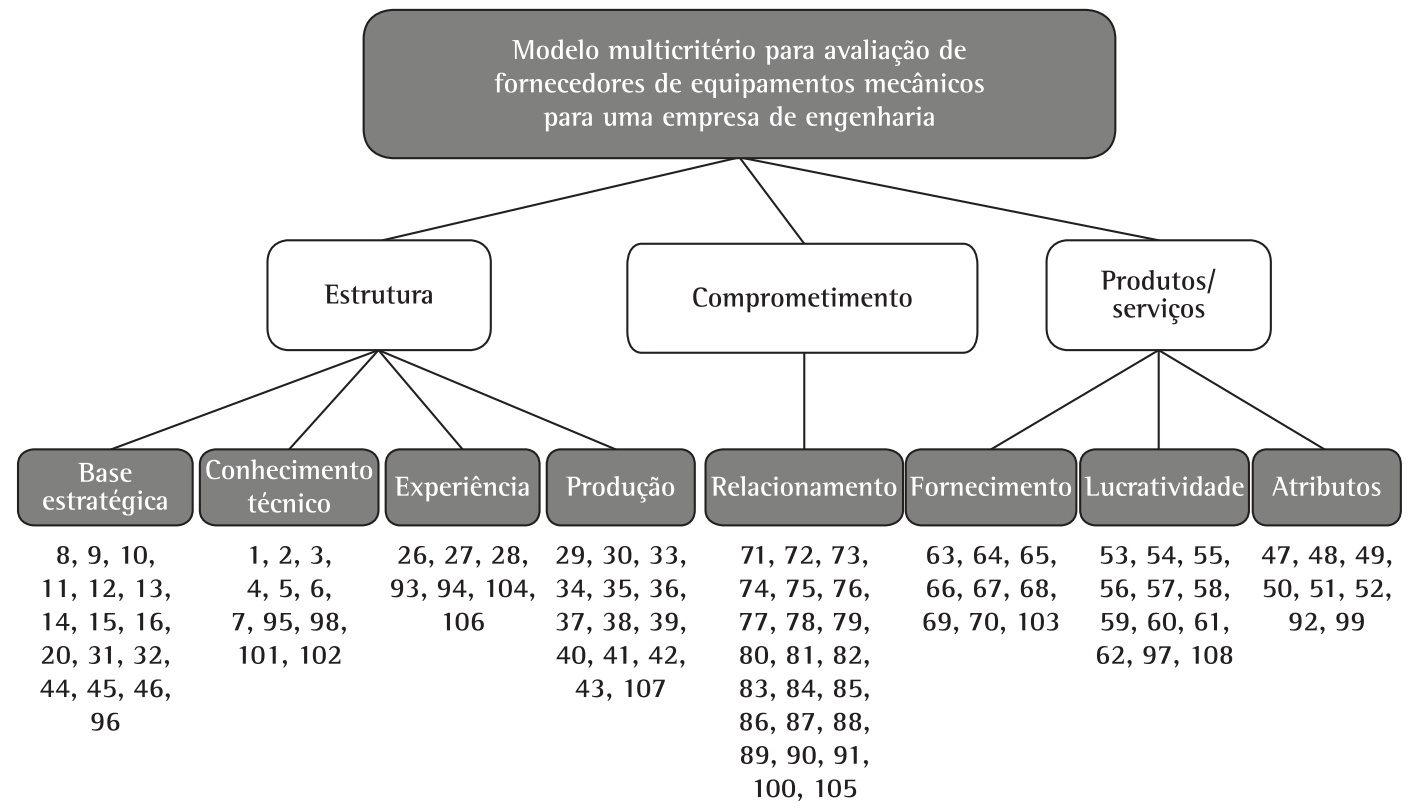

Figura 3. Áreas de preocupação e seus respectivos conceitos. Fonte: dados da pesquisa. 
previamente definidos e foram criados para responder às perguntas: Por que este conceito é importante? E como se pode obter tal conceito?

0 próximo passo é transferir a estrutura de ligações de influência para uma estrutura arborescente ou hierárquica de valor, na qual estarão representados os Pontos de Vista Fundamentais, PVFs. Este modelo conta com 8 PVFs.
0 rótulo do problema, com suas áreas de preocupação e respectivos pontos de vista fundamentais, pode ser visto na Figura 5.

\subsubsection{Estrutura hierárquica de valor e construção de descritores}

Os PVFs definidos representam o nível estratégico do modelo, não podendo ser mensurados. Portanto

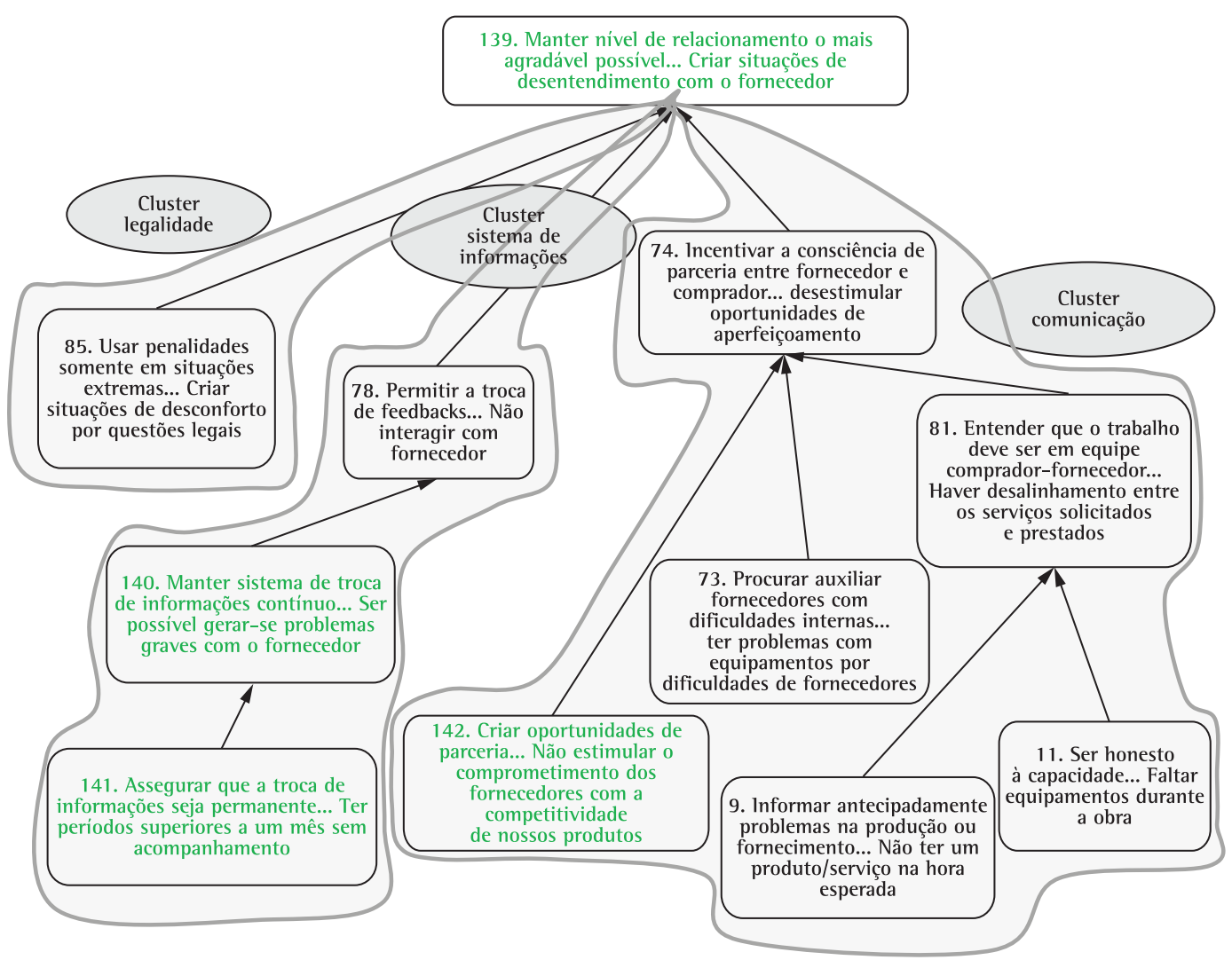

Figura 4. Mapa cognitivo para a área de preocupação comprometimento. Fonte: dados da pesquisa.

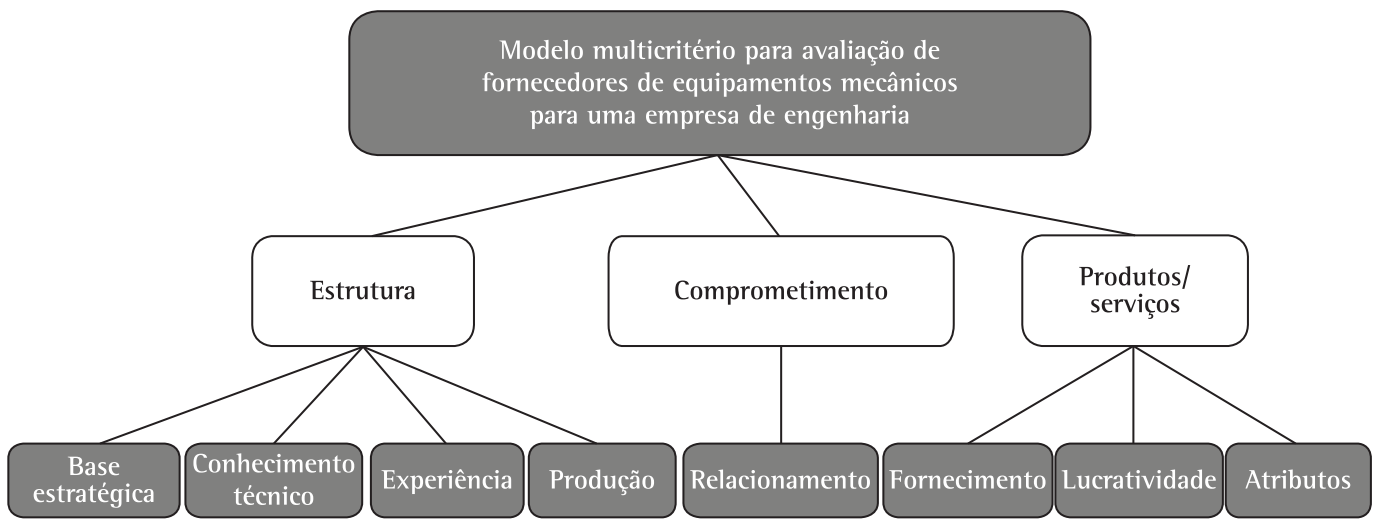

Figura 5. Árvore de valor para avaliação dos fornecedores da empresa. Fonte: dados da pesquisa. 


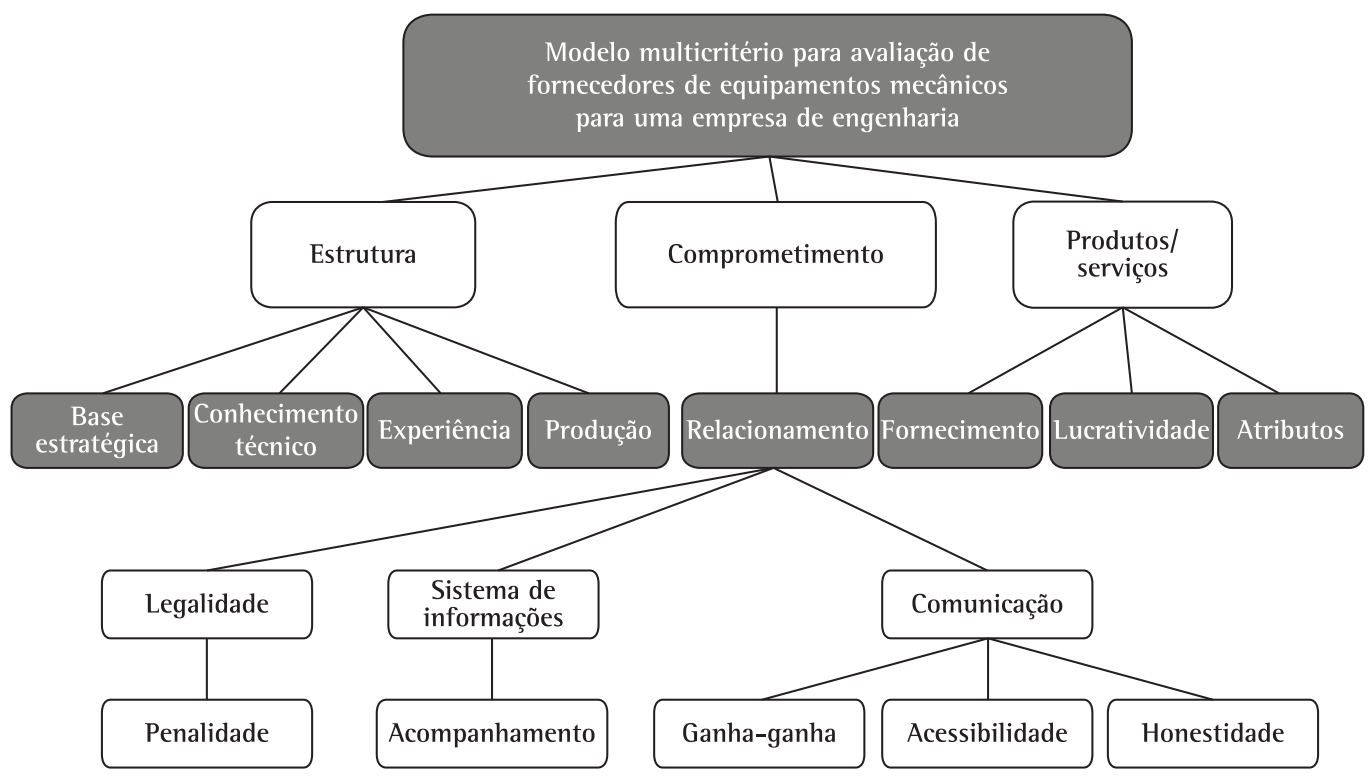

Figura 6. Pontos de vista elementares para o PVF relacionamento. Fonte: dados da pesquisa.

fez-se necessário decompor de forma contínua cada cluster a fim de se obter um ponto de vista elementar, PVE, que pudesse ser mensurado de forma objetiva e não ambígua (referência terceirizada).

0 modelo completo é composto por 43 PVEs. Os PVEs vinculados ao PVF relacionamento são exemplificados na Figura 6.

Dando continuidade ao modelo, a MCDA-C propõe a construção de escalas ordinais que permitam mensurar o desempenho de cada alternativa avaliada em cada ponto de vista. Essa escala, denominada descritor, possui níveis de impacto, sendo dois desses níveis de referência também chamados de âncoras. Os descritores devem ser construídos em um processo interativo, com a participação do decisor. Na Figura 7, apresenta-se o descritor do PVE honestidade.

De maneira mais ampla, os descritores são uma parte da avaliação de desempenho e não podem ser dela dissociados. Eles são instrumentos de gestão utilizados para medir alguma propriedade do contexto. Para Keeney e Raiffa (1976) e Ensslin, Montibeller e Noronha (2001), indicador de desempenho ou descritor pode ser entendido como a escala que mede o grau com que um objetivo é alcançado. E esse possui, segundo esses autores, seis propriedades desejáveis: i) mensurável; ii) operacional; iii) inteligivel; iv) homogêneo; v) permite distinguir desempenho melhor e pior; e vi) respeita as propriedades das escalas ordinais.

0 modelo global do caso estudado é composto de 43 descritores, que representam, no nível mais operacional, os aspectos considerados importantes para o contexto.

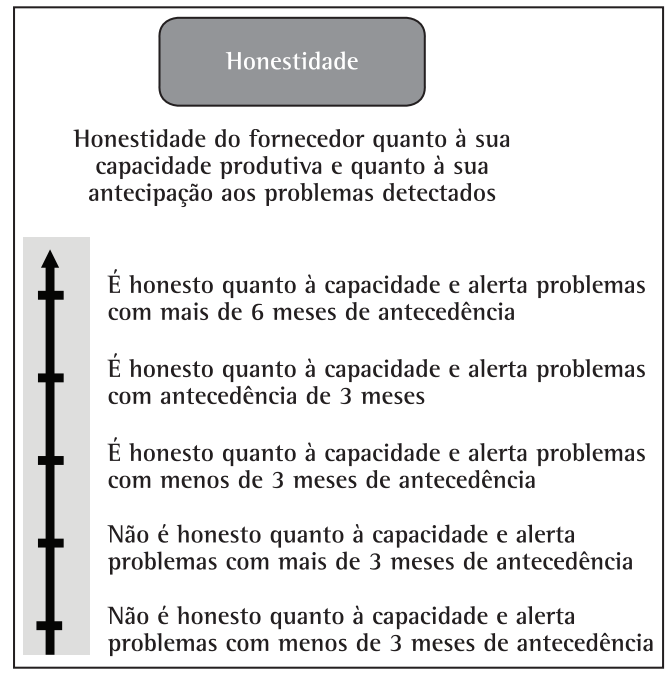

Figura 7. Descritor do PVE honestidade. Fonte: dados da pesquisa.

A Figura 8 apresenta a estrutura hierárquica de valor para o PVF relacionamento, com seus correspondentes PVEs e descritores, conforme explicitados na continuidade:

- Penalidade: número de vezes em que se fez necessário utilizar instrumentos legais durante a parceria com o fornecedor nos últimos cinco anos;

- Acompanhamento: frequência mensal com que o fornecedor costuma contatar a empresa espontaneamente para acompanhamento;

- Ganha-ganha: número de parcerias de desenvolvimento de inovações e ou aperfeiçoamento construídas com os fornecedores no último ano; 


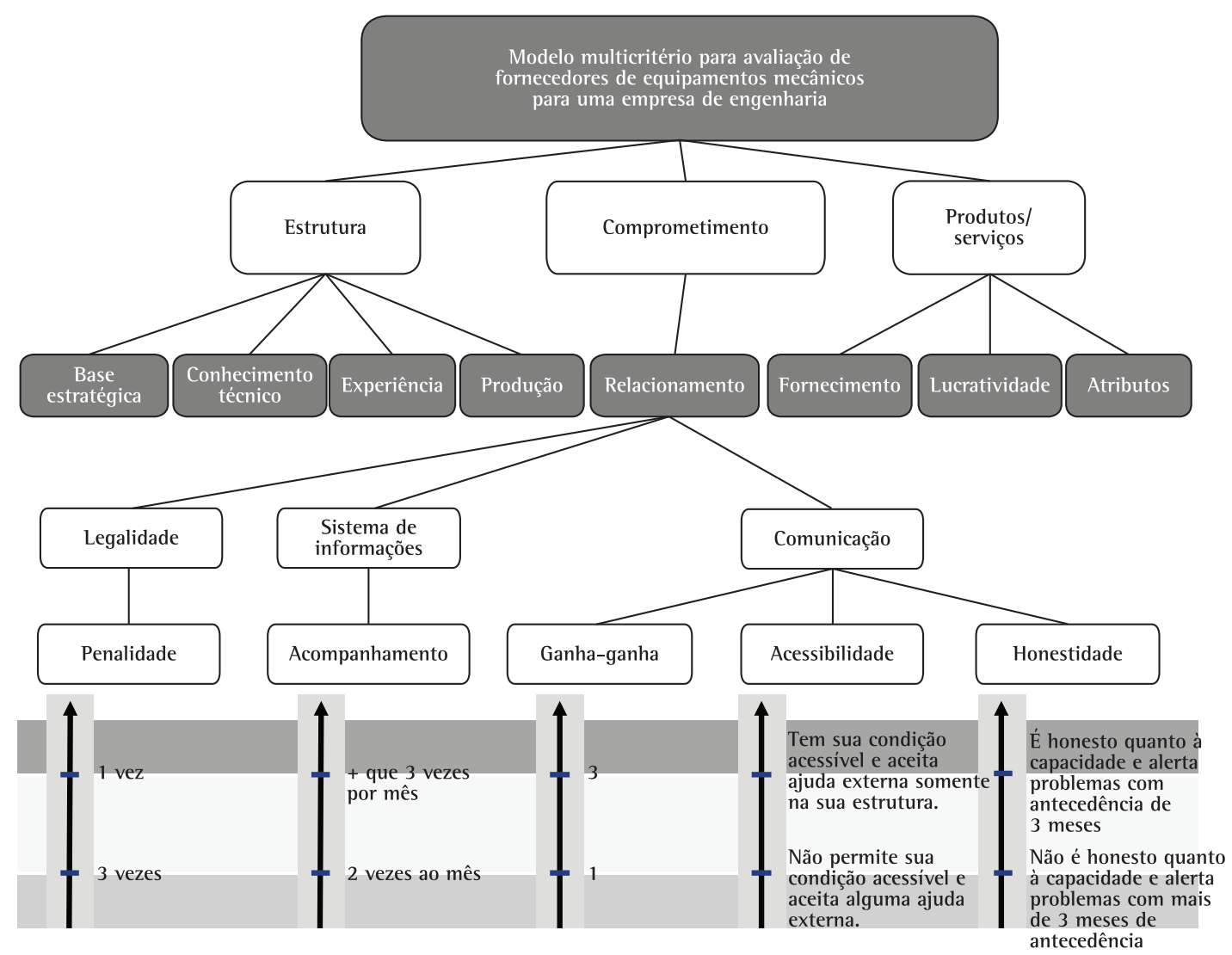

Figura 8. Estrutura hierárquica de valor para o PVF relacionamento, com seus PVEs e descritores. Fonte: dados da pesquisa.

- Acessibilidade: disponibilidade de informações da condição econômico-financeira do fornecedor e abertura para receber ajuda; e

- Honestidade: honestidade do fornecedor quanto à sua capacidade produtiva e quanto à sua antecipação de problemas detectados.

Nesse momento entende-se que o conhecimento necessário foi construído e dá-se início à etapa de avaliação, a qual transforma o conhecimento adquirido em um modelo matemático.

\subsection{Avaliação}

Bloom (1956), quando aborda o conceito avaliação no ambiente educacional, enuncia ser um julgamento do valor de algo, uma verificação de valor da evidência, reconhecimento da subjetividade, que dá possibilidade de comparação.

A fase de avaliação da MCDA-C busca compreender as diferenças de atratividade entre os níveis dos indicadores de desempenho, expressar como esses indicadores se compensam e, então, diagnosticar o status quo das alternativas em questão. Por último, essa seção ainda avalia o modelo de avaliação de desempenho quanto à sua sensibilidade.
Quadro 4. Métodos para transformação de escalas ordinais em cardinais.

\begin{tabular}{|c|c|}
\hline Julgamento & Método \\
\hline 1) Estimativas numéricas & $\begin{array}{c}\text { Pontuação: i) Direta, ii) Por categoria, } \\
\text { iii) Por razão }\end{array}$ \\
\hline 2) Indiferença & Bissecção \\
\hline $\begin{array}{l}\text { 3) Diferenças de } \\
\text { atratividade }\end{array}$ & Macbeth \\
\hline
\end{tabular}

Fonte: Adaptado de Ensslin et al. (2010b).

\subsubsection{Funções de valor}

As funções de valor são úteis, pois transformam o modelo qualitativo em quantitativo. Entendendo-se, aqui, que valor é a referência aos juízos do decisor, a importância de determinada coisa, estabelecida ou arbitrada.

Dessa maneira, utilizam-se métodos para diferenciar os níveis de atratividade a partir da percepção dos decisores. Segundo Ensslin et al. (2010a), são três os principais métodos para transformação de escalas ordinais em cardinais, conforme representado no Quadro 4.

Para o presente trabalho, é utilizado o método Macbeth. A ideia fundamental subjacente à concepção 


\begin{tabular}{|c|c|c|c|c|c|c|}
\hline & Nivel 1 & Nível 2 & Nivel 3 & Nível 4 & Nivel 5 & $\begin{array}{l}\text { Escala } \\
\text { Cardinal }\end{array}$ \\
\hline Nivel 1 & Nulo & Moderada & Forte & $\begin{array}{l}\text { Muito } \\
\text { Forte }\end{array}$ & Extrema & 150 \\
\hline Nível 2 & & Nulo & Moderada & Forte & $\begin{array}{l}\text { Muito } \\
\text { Forte }\end{array}$ & 100 \\
\hline Nivel 3 & & & Nulo & Moderada & Moderada & 50 \\
\hline Nivel 4 & & & & Nulo & Fraca & 0 \\
\hline Nivel 5 & & & & & Nulo & -33 \\
\hline \multicolumn{7}{|c|}{ ـ } \\
\hline \multicolumn{6}{|c|}{ Matriz de Julgamento } & $\begin{array}{l}\text { Funções } \\
\text { de Valor }\end{array}$ \\
\hline
\end{tabular}

Honestidade do fornecedor quanto à sua capacidade produtiva $\mathrm{e}$ quanto à sua antecipação aos problemas detectados

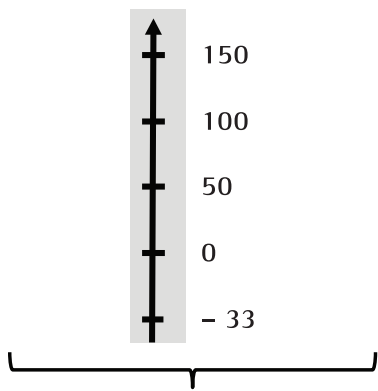

Escala Cardinal

Figura 9. Transformação do descritor honestidade em função de valor. Fonte: dados da pesquisa.

da abordagem do problema da construção de uma escala cardinal pelo julgamento de diferenças de atratividade, ao contrário dos outros expostos no Quadro 4, consiste em não colocar para o decisor questões que envolvam mais de duas ações. Propõe-se, pelo Macbeth, envolver apenas duas ações em alternativas de cada vez, colocando ao decisor perguntas mais simples que exigem dele apenas a elaboração de juízos absolutos sobre a diferença de atratividade entre as duas ações. Por exemplo, segundo um PVF, dados os impactos de duas ações potenciais nos níveis neutro e bom, sendo uma localmente mais atrativa que a outra, a diferença de atratividade pode ser desde extrema até muito fraca.

0 processo de interação utilizado na abordagem Macbeth leva em conta esse conhecimento de diferenças de atratividade. Concretamente, o método propõe ao decisor que exprima os seus juízos absolutos de diferença de atratividade por uma das seis categorias, de dimensão não necessariamente igual:

- C1 - diferença de atratividade muito fraca;

- C2 - diferença de atratividade fraca;

- C3 - diferença de atratividade moderada;

- C4 - diferença de atratividade forte;

- C5 - diferença de atratividade muito forte; e

- C6 - diferença de atratividade extrema.

0 método permite, ainda, que testes de consistência semântica sejam realizados em cada descritor que tem sua escala transformada de ordinal para cardinal. Isto é dizer que o Macbeth não permite o decisor julgar, por exemplo, uma ação "a" C6 mais atrativa que "b", a mesma ação "a" C4 mais atrativa que "c" e, por último, julgar "b" $\mathrm{C} 1$ mais atrativa que "c". $\mathrm{Na}$ linha de raciocínio lógico, "c" deve ser mais atrativa

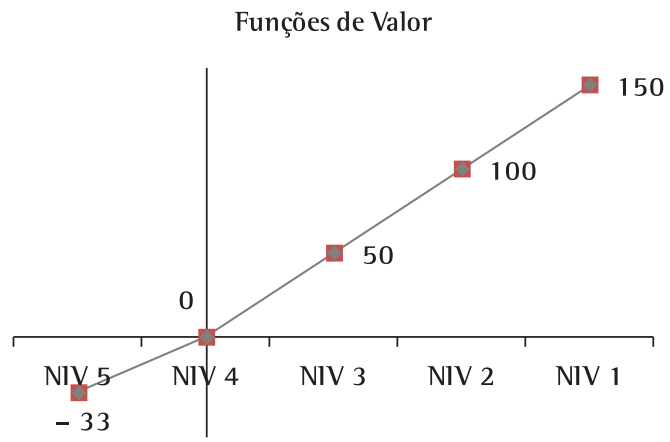

Figura 10. Representação gráfica da função de valor do descritor honestidade. Fonte: dados da pesquisa.

que "b". Bana e Costa et al. (1999) defendem que esse tipo de teste insere-se perfeitamente na perspectiva interativa de aprendizagem para o apoio à decisão e a qualquer ferramenta técnica que deva subordinar-se.

No presente estudo, todos os PVEs foram expostos aos decisores que tiveram de julgar, de acordo com as seis categorias explanadas, a diferença de atratividade entre os níveis dos descritores. Baseada nas respostas dadas pelo decisor foi possível construir a matriz de julgamentos, cujos valores servem de inputs para o software calcular as funções de valor. Dessa forma, constrói-se a escala cardinal a partir da escala ordinal. A Figura 9 apresenta tal construção usando, como exemplo, o PVE honestidade.

A Figura 10 exibe a representação gráfica dessa função de valor.

Expandindo essa construção para o modelo tem-se como exemplo a Figura 11, que mostra todas as escalas cardinais.

Segundo Ensslin et al. (2010b), ao concluir a construção das funções de valor, a metodologia 
MCDA-C disponibiliza ao decisor um entendimento que the possibilita viabilizar a mensuração cardinal de cada aspecto operacional considerado relevante. Contudo, não lhe permite ainda visualizar a mensuração dos aspectos julgados estratégicos, os pontos de vista fundamentais e nem os táticos, os pontos de vista elementares intermediários. Para dar prosseguimento ao processo de construção do entendimento, devem ser incorporadas informações que permitam integrar as escalas cardinais. Esse é o propósito da etapa seguinte da metodologia MCDA-C.

\subsubsection{Taxas de compensação locais}

Para se ter uma avaliação global, isto é, fazer com que uma mudança de desempenho em um descritor possa ser comparada com mudanças de desempenho em outros descritores, constroem-se as taxas de substituição que, de acordo Ensslin, Montibeller e
Noronha (2001), são como constantes de escala, que transformam valores locais de preferência (avaliados em cada critério) em valores globais. Dessa forma, cada critério é representado por uma taxa de substituição, a qual é a importância relativa que um descritor tem em relação aos demais, comparando-os através dos níveis de referência bom e neutro. Tais taxas, quando combinadas, levam a uma avaliação global que permite ao decisor comparar as alternativas disponíveis. Um dos métodos que pode ser utilizado para a obtenção das taxas é o da comparação par a par, análogo ao citado anteriormente (julgamento semântico), o qual também faz uso da lógica Macbeth. A escolha deste método deve-se à não exigência do decisor realizar um julgamento por meios numéricos, e sim semânticos.

Dando sequência ao estudo de caso, faz-se necessário indicar qual estrutura hierárquica será integrada. A Figura 12 apresenta em destaque a estrutura em questão.

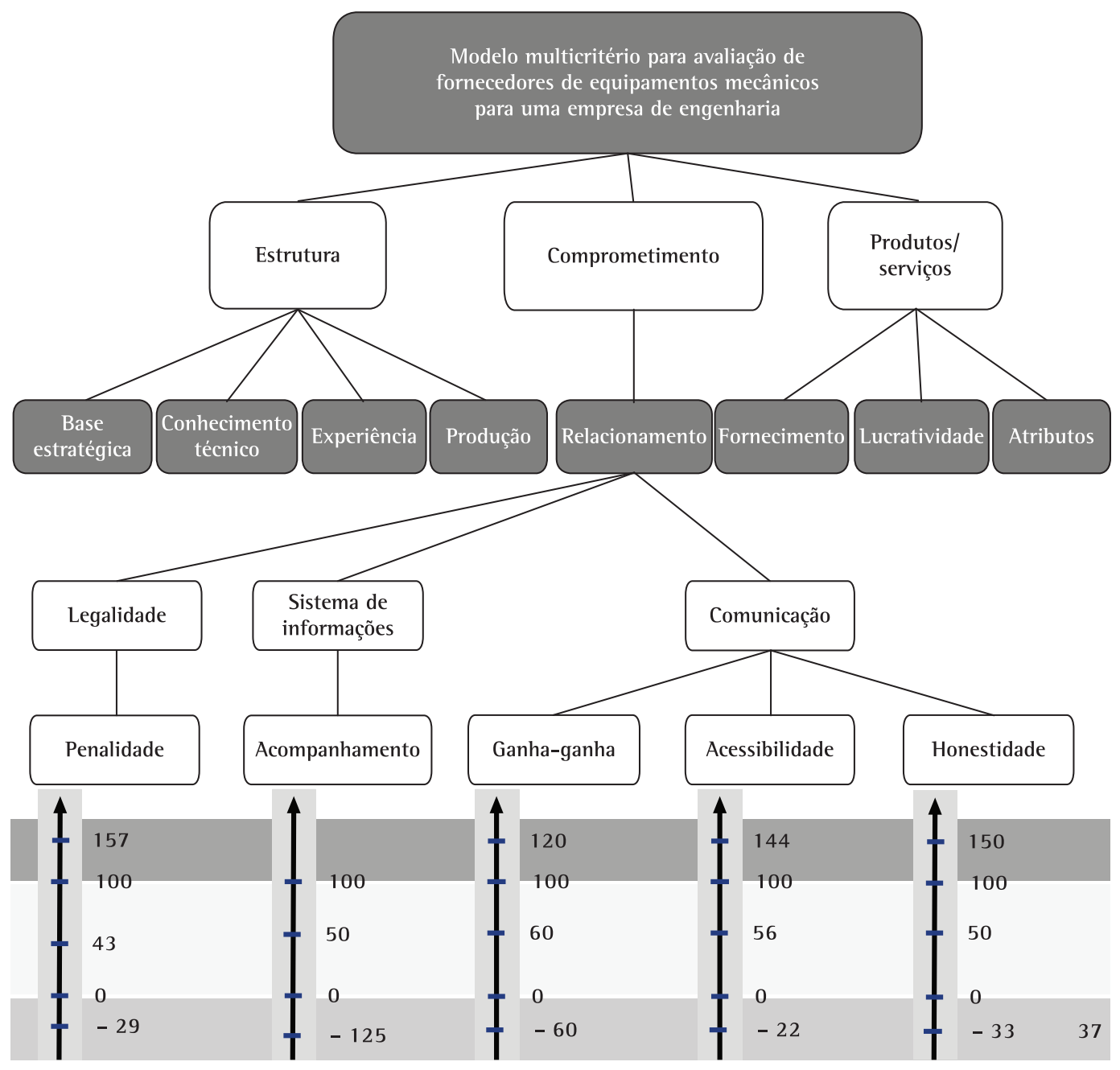

Figura 11. Escalas cardinais do PVF relacionamento. Fonte: dados da pesquisa. 
Nesse contexto, é essencial conhecer os descritores que compõem os PVEs que serão integrados, com seus respectivos níveis de referência, conforme apresenta a Figura 13.

Uma vez explicitados os descritores, com seus níveis de ancoragem, deve-se agora indicar as alternativas construídas para a comparação par a par. Para tanto, é preciso criar ações potenciais que representem a contribuição da passagem do nível neutro para o nível bom, em cada um dos critérios que se deseja determinar as taxas, assim como uma ação de referência com desempenho neutro em todos os pontos de vista. As alternativas com as ações potenciais são vistas na Figura 14.
Após a criação das alternativas, deve-se ordená-las de acordo com a preferência, julgada pelo decisor, podendo utilizar-se da matriz de Roberts. Uma vez que essas estão ordenadas de forma matricial, cada vez que o decisor optar pela alternativa da linha em detrimento da alternativa da coluna, a alternativa que se encontra na linha recebe 1 ponto. Essa matriz é apresentada na Figura 15.

Uma vez de posse da ordenação de preferência das alternativas, retorna-se ao Macbeth, que, seguindo a mesma lógica anterior, assinala as taxas de substituição. Esse processo pode ser visto na Tabela 1.

A seguir, apresenta-se a Figura 16 como representação do resultado na estrutura. Neste

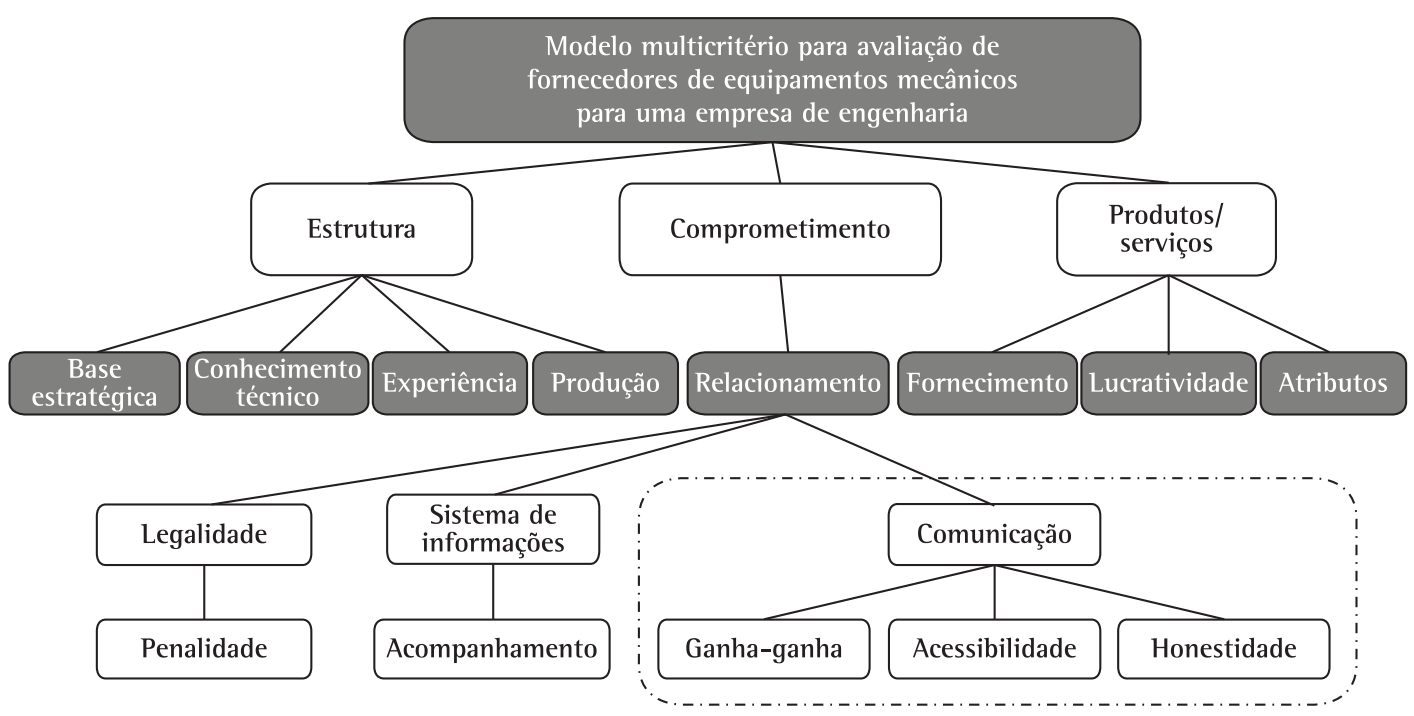

Figura 12. Estrutura hierárquica de valor, com destaque as PVEs ganha-ganha, acessibilidade e honestidade. Fonte: dados da pesquisa.

Ganha-ganha

Número de parcerias de desenvolvimento de inovações e ou aperfeiçoamento construido com os

forneced ores no último ano

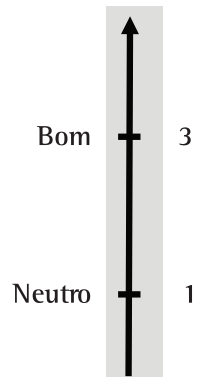

Acessibilidade

Disponibilidade de informações da condição econômicofinanceira do forneced or e abertura para receber ajuda

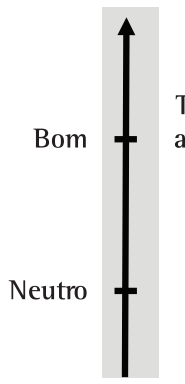

Tem sua condição acessivel e aceita ajuda externa somente na sua Estrutura.

Não permite sua condição acessivel e aceita alguma ajuda externa.
Honestidade

Honestidade do forneced or quanto à sua capacidade produtiva e quanto à sua antecipação aos problemas detectados

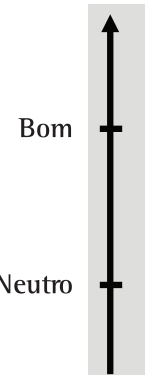

É honesto quanto à capacidade e alerta problemas com antecedência de 3 meses

Não é honesto quanto à capacidade e alerta problemas com mais de 3 meses de antecedência

Figura 13. Descritores do PVE comunicação a serem integrados. Fonte: dados da pesquisa. 
A1

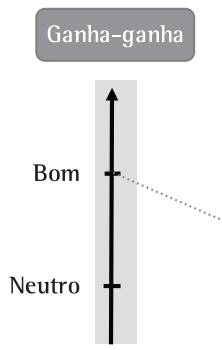

Ganha-ganha
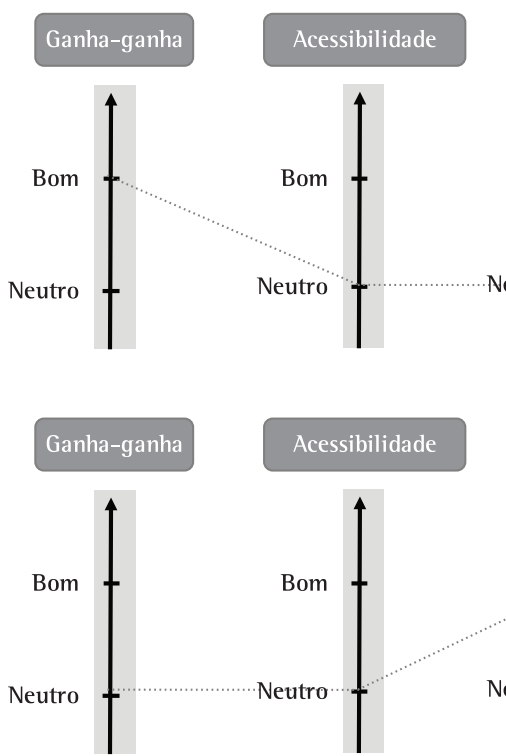

A3
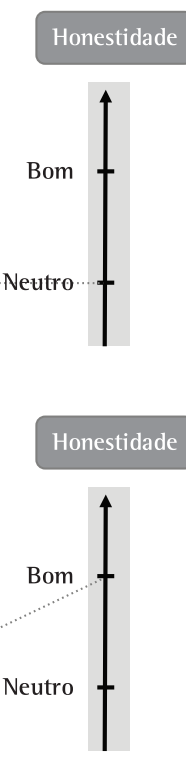

Figura 14. Alternativas $\mathrm{A} 1, \mathrm{~A} 2, \mathrm{~A} 3$ e $\mathrm{A} 0$. Fonte: dados da pesquisa.

\begin{tabular}{|c|c|c|c|c|c|c|}
\hline & A1 & A2 & A3 & A0 & Soma & Ordem \\
\hline $\mathrm{A} 1$ & & 1 & 0 & 1 & 2 & $2^{\circ}$ \\
\hline $\mathrm{A} 2$ & 0 & & 0 & 1 & 1 & $3^{\circ}$ \\
\hline $\mathrm{A} 3$ & 1 & 1 & & 1 & 3 & $1^{\circ}$ \\
\hline $\mathrm{A} 0$ & 0 & 0 & 0 & & 0 & $4^{\circ}$ \\
\hline
\end{tabular}

Figura 15. Matriz de Roberts de comparação das alternativas A1, A2, A3 e A0. Fonte: dados da pesquisa.

Tabela 1. Taxas de substituição calculadas pelo software Macbeth.

\begin{tabular}{cccccc}
\hline & A3 & A1 & A2 & A0 & $\begin{array}{c}\text { Escala } \\
\text { Atual }\end{array}$ \\
\hline A3 & Nulo & Moderada & Forte & Muito & Forte \\
A1 & & Nulo & Moderada & Forte & 31.00 \\
A2 & & & Nulo & Moderada & 16.00 \\
A0 & & & & Nulo & 0 \\
\hline
\end{tabular}

Fonte: dados da pesquisa.

ponto, vale ressaltar que a principal diferença entre as taxas de substituição e os pesos utilizados por todos os modelos analisados na literatura é que as taxas são obtidas pela comparação par a par dos critérios de avaliação, analisando-se níveis de referência previamente estabelecidos (bom e neutro). Assim, as taxas de substituição não ficam vulneráveis com a inserção de novas alternativas e/ou novos níveis de desempenho na escala construída, pois a taxa foi definida para um intervalo determinado na escala de avaliação.

\subsubsection{Taxas de compensação global e equação global}

Processo análogo é feito para a determinação das taxas de compensação globais. A partir dessas taxas é possível traçar o perfil de impacto de cada alternativa a fim de avaliar e selecionar o fornecedor mais adequado ao empreendimento no momento.

Na Figura 17, apresenta-se a estrutura do PVF relacionamento.

A equação global para este PVF é explicitada a seguir:

$V(\alpha) \operatorname{PVF}($ Re lacionamento $)=0,28 * V$ Penalidade $(\alpha)$

$+0,11^{*} V$ Acompanhamento $(\alpha)$

$+0,61\left[0,31^{*} V\right.$ Ganha - Ganha $(\alpha)+0,16 * V$ Acessibilidade $(\alpha)$

$+0,53 * V$ Honestidade $(\alpha)]$

A Figura 18 mostra a estrutura hierárquica de valor do modelo completa com as taxas de substituição de todos os PVFs.

Compreendendo que cada PVF tem seu modelo próprio, a soma de todos estes modelos leva ao modelo global. A equação global é vista a seguir:

\footnotetext{
$V(\alpha)=0,3 .\left[0.3{ }^{*}\right.$ VBaseEstrag $(\alpha)+0,2{ }^{*} V \operatorname{ConhecTec}(\alpha)$

$\left.+0,3{ }^{*} V \operatorname{Exp}(\alpha)+0,2{ }^{*} V \operatorname{Prod}(\alpha)\right]+0,2{ }^{*} V$ Re lacionamento $(\alpha)$

$+0,5 *[0,14 *$ VFornecimento $(\alpha)+0,36 *$ VLucratividade

$+0,5 *$ VAtributos $(\alpha)$ ]
} 
Nesse ponto, torna-se possível a utilização prática do modelo para auxílio da gestão da empresa em relação à avaliação de fornecedores. Dessa forma, os coordenadores da área de suprimentos da empresa de engenharia têm a possibilidade de avaliar proponentes e verificar quais deles possuem um alinhamento estratégico com a empresa.

\subsubsection{Identificação do perfil das alternativas}

A título de ilustração do caso, os coordenadores da área de suprimentos avaliaram três proponentes de equipamentos mecânicos principais. Dessa forma foi possível identificar o perfil de cada um e levantar a pontuação, como aponta a Figura 19.

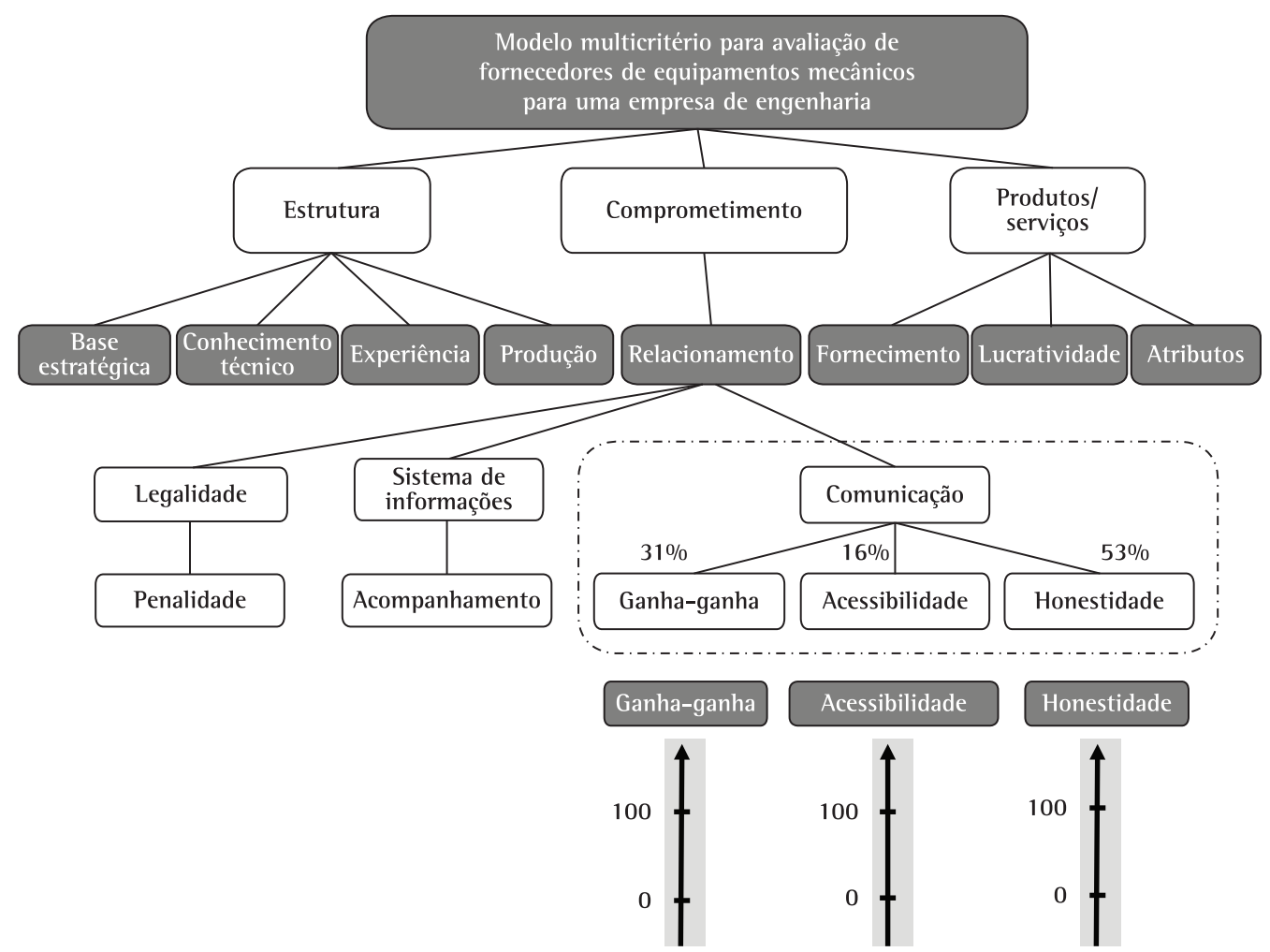

Figura 16. Taxas de substituição dos PVEs ganha-ganha, acessibilidade” e honestidade. Fonte: dados da pesquisa.

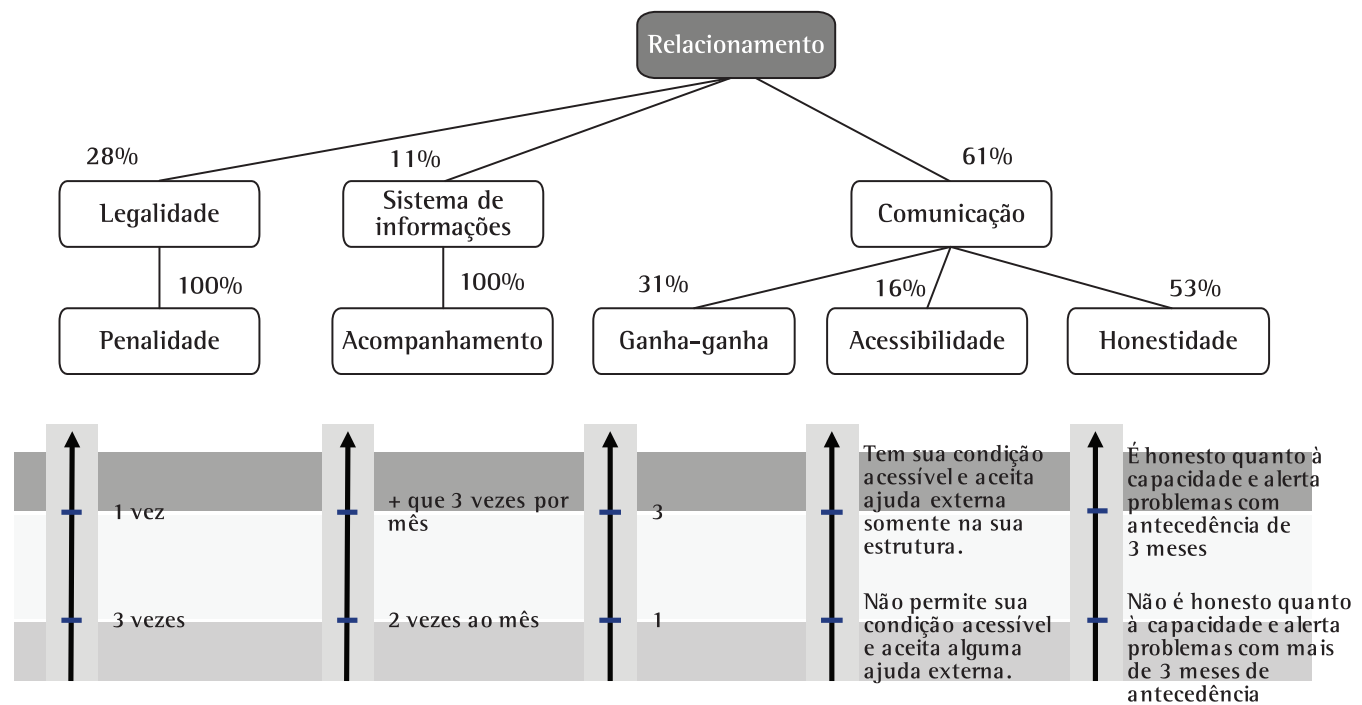

Figura 17. Taxas de substituição do PVF relacionamento. Fonte: dados da pesquisa. 
Observando-se a estrutura, pode-se perceber que o proponente 1 se mostrou superior na grande maioria dos PVFs, tendo alcançado uma pontuação de excelência no PVF relacionamento. De qualquer forma, em alguns PVFs como fornecimento, experiência e conhecimento técnico e base estratégica, todos os fornecedores avaliados apresentam pontuação muito próxima e em um nível razoavelmente baixo, mesmo que ainda dentro do nível de mercado, o que indica um desalinhamento estratégico entre proponentes e compradora. Ou seja, há muitas oportunidades de melhoria a serem trabalhadas de ambas as partes.

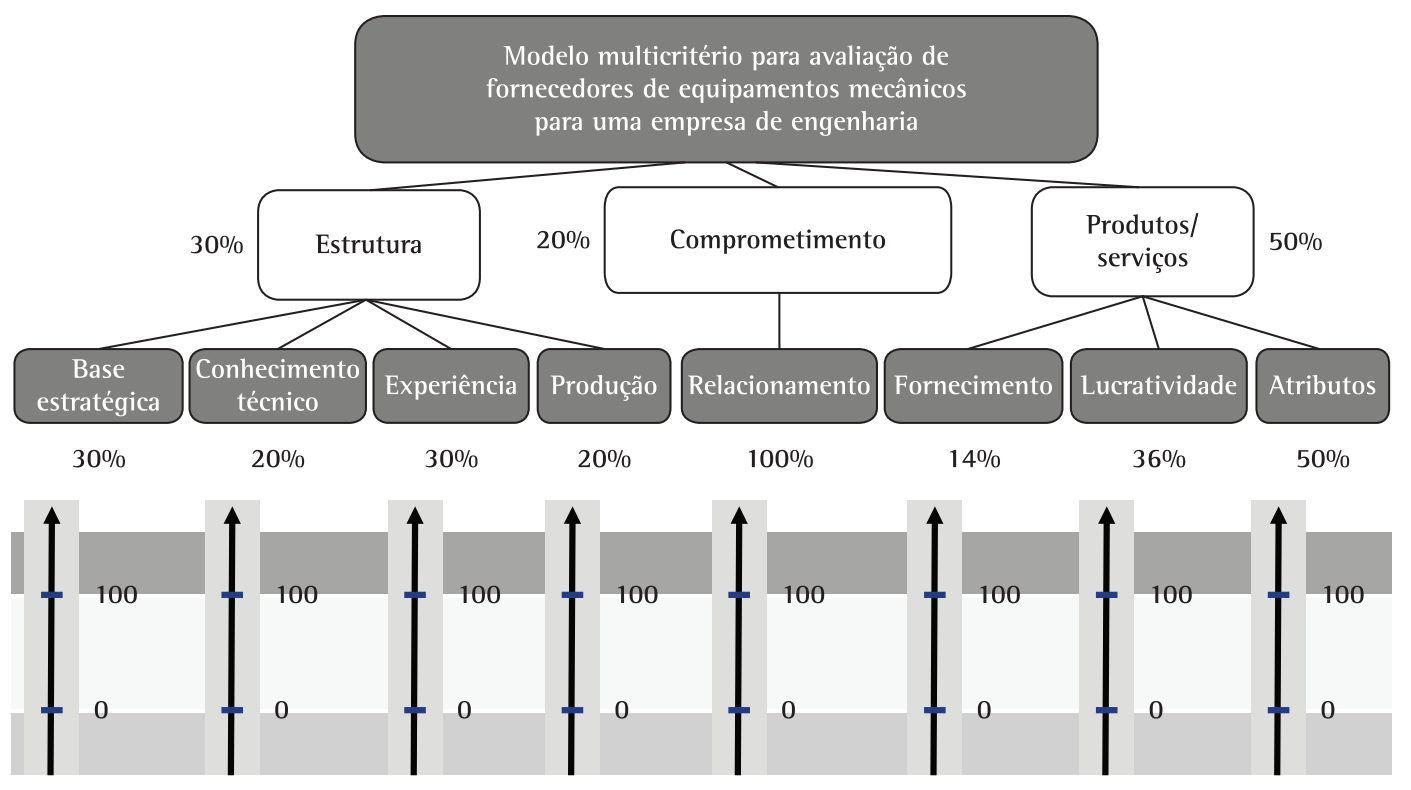

Figura 18. Taxas de substituição dos PVFs. Fonte: dados da pesquisa.

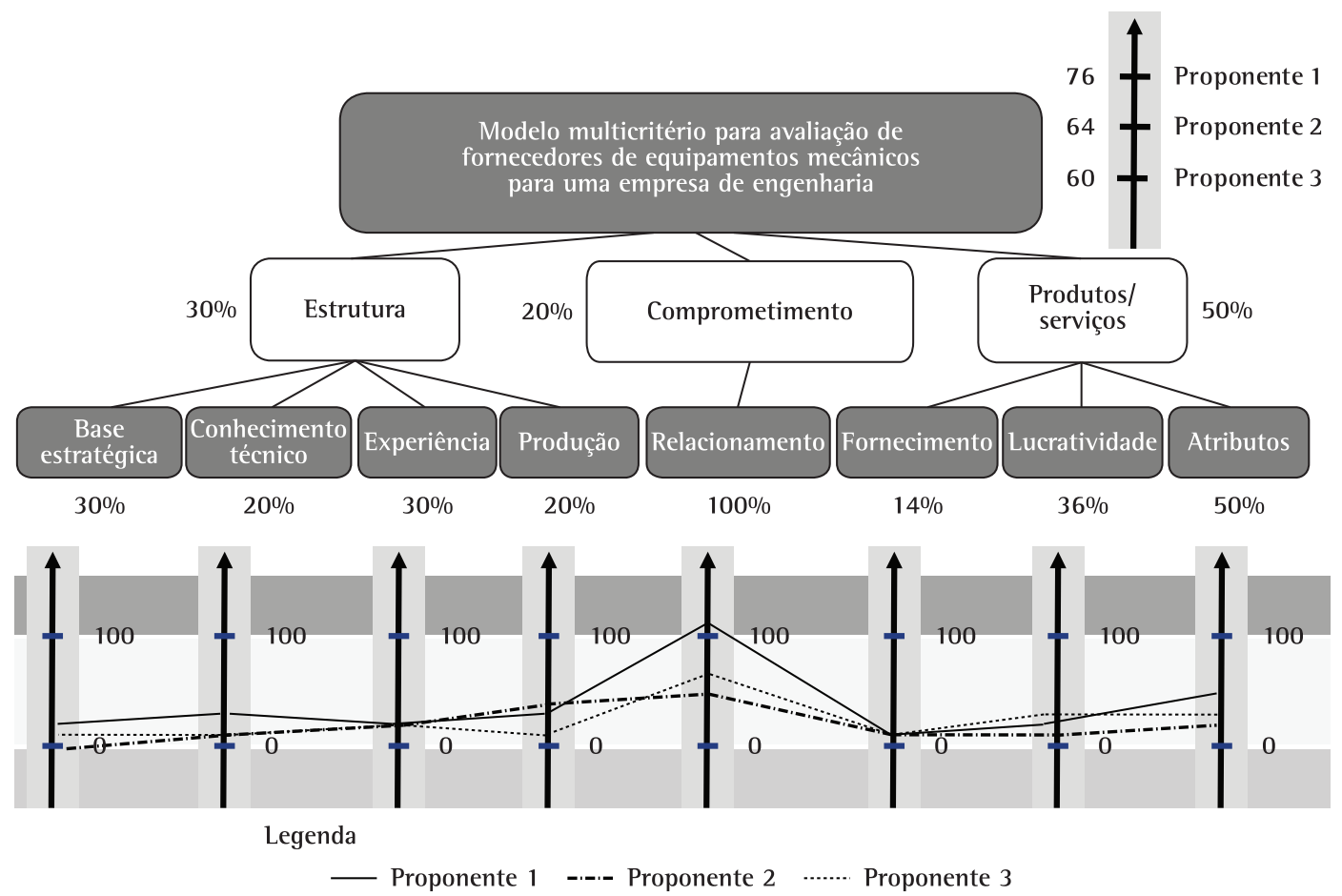

Figura 19. Perfil de impacto do status quo de três proponentes a fornecedores de equipamentos mecânicos. Fonte: dados da pesquisa. 


\subsection{Recomendações}

Para a metodologia MCDA-C, a etapa de recomendações serve ao decisor como apoio na identificação nas formas de melhoria do estado atual de seu objeto de estudo. Assim, possibilita identificar as consequências que essas melhorias terão em nível estratégico. Essa etapa não é identificada como reguladora do que deve ser feito e sim como auxiliadora na compreensão do estado atual, demonstrando as consequências que uma decisão tomada pode acarretar (KEENEY; RAIFFA, 1976). Com isso, a etapa se inicia identificando os PVFs nos quais é desejado aperfeiçoar o estado atual, proporcionando melhoria no desempenho global. Por análise de importância, conforme Tabela 2, evidencia-se que o PVF que mais impacta no desempenho global é atributos, com 25\%, sendo assim, o objeto de estudo, pois também é um dos PVFs com desempenho mais comprometedor. Assim, é realizado o mesmo procedimento de análise de importância no impacto, quanto ao valor do PVF. Pela Tabela 3 é possível visualizar os indicadores que mais impactam no desempenho do PVF atributos.

Após essa análise, fez-se necessário verificar quais desses indicadores estão em níveis mais críticos. $\mathrm{Na}$ Figura 20 é possível visualizar que, dentre os três indicadores de maior impacto nos PVEs, o indicador em estado mais crítico é fabricação, portanto esse indicador é o mais apropriado para melhoria do status quo e objeto do exemplo, conforme a Figura 21.

Tabela 2. Escala de importância global dos PVFs.

\begin{tabular}{cccc}
\hline PVF & $\begin{array}{c}\text { Áreas de } \\
\text { Interesse }\end{array}$ & PVF (\%) & $\begin{array}{c}\text { Impacto } \\
\text { Global (\%) }\end{array}$ \\
\hline $\begin{array}{c}\text { Base Estratégia } \\
\text { Conhecimento } \\
\text { Técnico }\end{array}$ & 30 & 30 & 9 \\
Experiência & & 20 & 6 \\
Produção & 20 & 30 & 9 \\
\hline Relacionamento & & 100 & 6 \\
\hline Fornecimento & & 14 & 20 \\
Lucratividade & 50 & 36 & 7 \\
Atributo & & 50 & 25 \\
\hline
\end{tabular}

Tabela 3. Escala de importância dos indicadores no PVF atributos.

\begin{tabular}{cccc}
\hline PVF & PVE's (\%) & Indicador (\%) & $\begin{array}{c}\text { Impacto PVF } \\
\text { (\%) }\end{array}$ \\
\hline $\begin{array}{c}\text { Adequamento } \\
\text { ao Pedido }\end{array}$ & 24 & 100 & 24 \\
$\begin{array}{c}\text { Diligenciamento } \\
\text { Cronograma }\end{array}$ & 41 & 40 & 16 \\
PIT & & 60 & 25 \\
Fabricação & 35 & 33 & 12 \\
\hline
\end{tabular}

Fonte: dados da pesquisa.

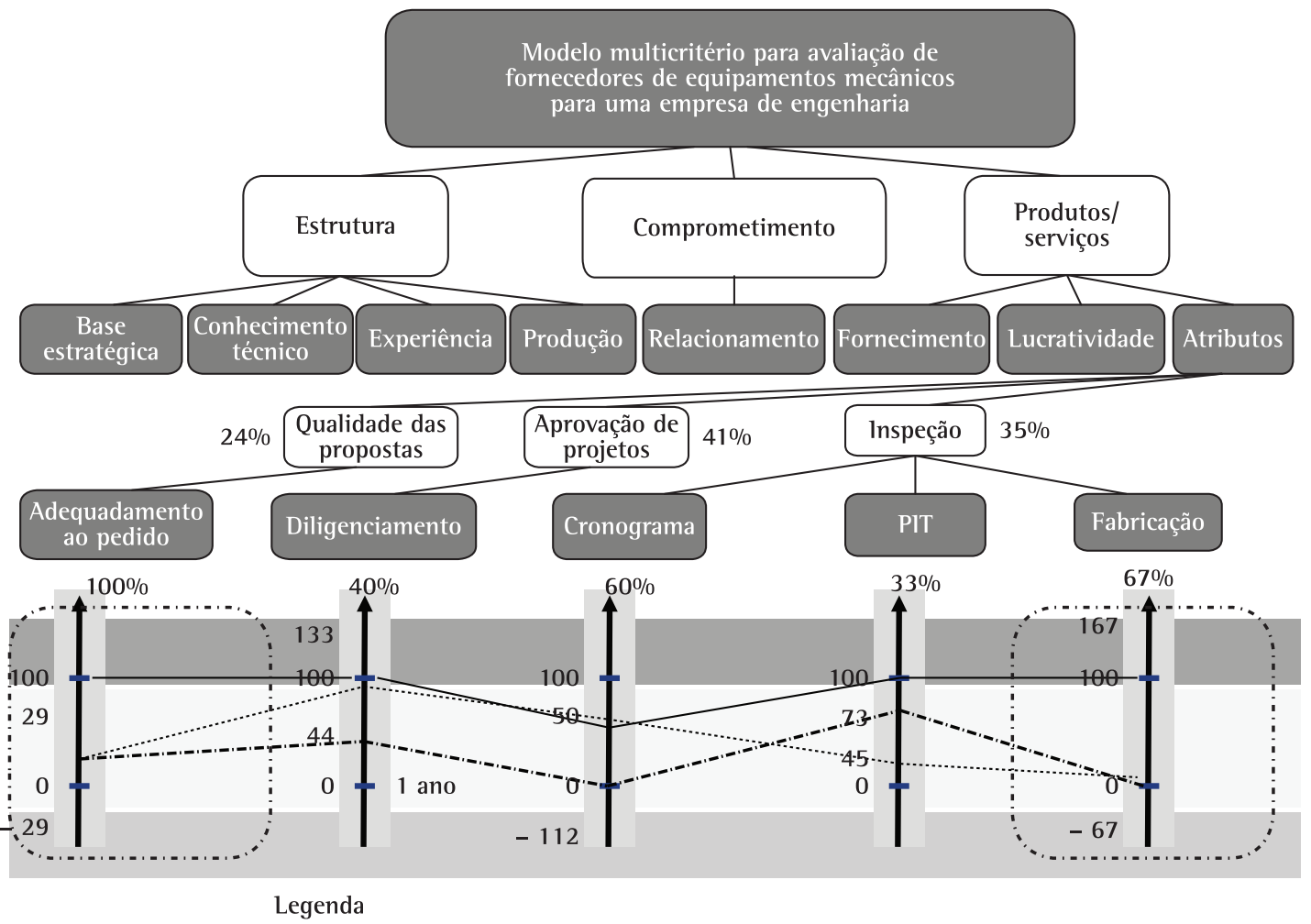

— Proponente 1 -...- Proponente 2 ....... Proponente 3

Figura 20. Perfil de impacto dos indicadores no PVF atributos. Fonte: dados da pesquisa. 


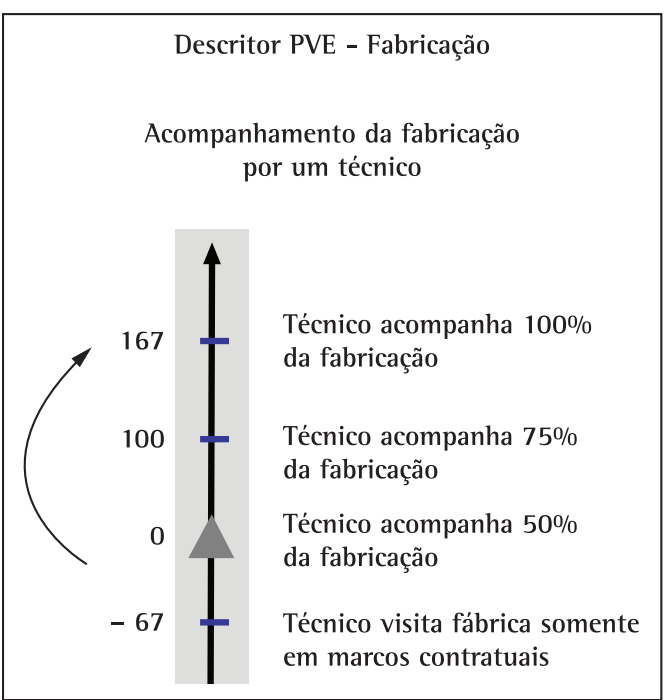

Figura 21. Alteração no desempenho no descritor do PVE. Fonte: dados da pesquisa.

Sendo esse procedimento realizado com os demais indicadores PVFs, é possível aumentar o desempenho do perfil de impacto da Figura 20 - é possível elevar a performance do PVF atributos em até 47\%.

Percebe-se, então, a importância de recomendações na metodologia MCDA-C para a identificação dos seguintes pontos:

- Proporcionar ao decisor o conhecimento para o aperfeiçoamento;

- Quais PVFs e quais indicadores é conveniente estudar e aperfeiçoar; e

- Quais as consequências da implementação nos níveis operacional (PVE), tático (PVF) e estratégico (global).

0 decisor poderá analisar da mesma forma os demais indicadores, melhorando seus desempenhos atuais.

Assim, a metodologia MCDA-C mantém seus pressupostos construtivistas através das três fases: estruturação, avaliação e recomendações, atuando de forma a identificar as ações onde suas consequências impactam de forma a atingir seus objetivos (ENSSLIN et al., 2010b).

\section{Considerações finais}

No atual cenário de concorrência acirrada, há uma maior necessidade dos executivos adotarem uma postura mais estratégica (FERREIRA et al., 2008). No âmbito prático, o presente trabalho torna-se digno por intentar contribuir com melhorias nas obras de infraestrutura em território brasileiro, propondo-se, nesse sentido, a avaliar peças fundamentais na construção de usinas hidrelétricas quanto aos fornecedores de equipamentos mecânicos. Consolida-se seu reconhecimento quando, no circuito teórico, expande as fronteiras do conhecimento na área de avaliação de desempenho, desenvolvendo, dessa maneira, um modelo de gestão para apoiar decisões sob o paradigma do construtivismo. Ao combinar esses ingredientes, tem-se uma obra que coopera com a evolução científica da humanidade.

Desde o preâmbulo, o enfoque geral foi viabilizar maneiras de aumentar a competitividade da organização em estudo. Por se tratar de um contexto complexo, com interesses conflitantes, foi utilizada a metodologia MCDA-C como instrumento de intervenção, a qual tem base na pesquisa operacional Soft. A partir disso, tornou-se possível a construção de um modelo para avaliar de fornecedores com bases fixadas na avaliação de desempenho.

0 estudo iniciou a estrutura do modelo a partir da contextualização do cenário, definição dos atores, do rótulo e do sumário; complementou com os levantamentos de elementos primários de avaliação e formulação de conceitos; e completou quando desenvolveu e desenhou as áreas de preocupação, os mapas cognitivos, os pontos de vista fundamentais e os descritores. A avaliação foi realizada em três momentos, sendo que, no primeiro, construíram-se as funções de valor para cada descritor e suas taxas de compensação; taxas de compensação também foram constituídas para as áreas de preocupação, bem como pontos de vista fundamentais para, então, alcançar a equação global do modelo em um segundo momento; por último, proponentes foram submetidos ao modelo e seus perfis identificados. Ao fim das duas primeiras etapas da aplicação da MCDA-C, muito conhecimento sobre o contexto dos proponentes já havia sido construído. Chegou-se ao nível em que seus status quo estavam devidamente mapeados, concebendo um ambiente propício para aperfeiçoamentos. Nesse ponto, formularam-se as recomendações, as quais supostamente levarão os avaliados do nível global atual a um nível desejado.

No desfecho, constata-se o sucesso do estudo com o cumprimento dos objetivos geral e específicos. Há de ressaltar, ainda, que hoje, com esta poderosa ferramenta, é possivel entender o contexto, captar seus aspectos importantes, mensurá-los, desenhar sua integração e diagnosticar diferentes fornecedores, desse modo fornecendo credibilidade, coerência e transparência ao processo decisório. Tudo solidificado em bases de conhecimento gerado.

No tocante a futuros trabalhos, as recomendações que emergem são: i) na aplicação da metodologia, sugere-se o envolvimento dos clientes da empresa de engenharia e dos próprios fornecedores como 
atores do modelo, com o objetivo de se aproveitar as sinergias existentes durante o processo; ii) sobre o comportamento dos pesquisadores, aconselha-se que esses devem sempre considerar a exaustividade do estudo em todas as etapas, isto é, concordar que o processo de geração de conhecimento é demorado e exige persistência; iii) a respeito da escolha de contextos para futuras pesquisas e aplicações da MCDA-C, encoraja-se a busca por ambientes que, quando aperfeiçoados, venham a contribuir com o progresso da humanidade.

\section{Referências}

BANA E COSTA, C. A. et al. Decision Support Systems in action: Integrated application in a multicriteria decision aid process. European Journal of Operational Research, v. 113, n. 2, p. 315-335, 1999. http://dx.doi.org/10.1016/ S0377-2217(98)00219-7

BORTOLUZZI, S. C.; ENSSLIN, S. R.; ENSSLIN, L. Avaliação de desempenho dos aspectos tangíveis e intangíveis da área de mercado: Estudo de caso em uma média empresa industrial. Revista Brasileira de Gestão de Negócios (RBGM), v. 12, n. 37, p. 425-446, 2010.

BORTOLUZZI, S. C.; ENSSLIN, S. R.; ENSSLIN, L. Avaliação de desempenho multicritério como apoio à gestão de empresas: Aplicação em uma empresa de serviços. Gestão \& Produção, v. 18, n. 3, p. 633-650, 2011. http://dx.doi. org/10.1590/S0104-530X2011000300014

BL00M, B. S. Taxonomy of educational objectives: The classification of educational goals - Handbook l, cognitive domain. New York: Longmans; Toronto: Green, 1956.

BRASIL. Ministério do Planejamento, Orçamento e Gestão. Assuntos Econômicos. Brasília, 2010a. Disponível em: <http:/www.planejamento.gov.br>. Acesso em: 02 set. 2010.

BRASIL. Ministério do Trabalho. Portal do Trabalho e Emprego. Brasília, 2010b. Disponivel em: <http:/www. mte.gov.br>. Acesso em: 02 set. 2010.

BRASIL. Programa de Aceleração do Crescimento. Brasília, 2010c. Disponível em: <http:/www.brasil.gov. br/pac>. Acesso em: 06 set. 2010.

DA ROSA, F. S. et al. Gestão da evidenciação ambiental: Um estudo sobre as potencialidades e oportunidades do tema. Engenharia Sanitária e Ambiental, v. 16, n. 2, p. 157-166, 2011. http://dx.doi.org/10.1590/S141341522011000200009

DELLA BRUNA JUNIOR, E.; ENSSLIN, L.; ENSSLIN, S. R. Supply chain performance evaluation: A case study in a company of equipment for refrigeration. In: INTERNATIONAL TECHNOLOGY MANAGEMENT CONFERENCE - ITMC, 2011, San Jose. Anais... IEEE International, 2011.

ENSSLIN, L.; MONTIBELLER, G. N.; NORONHA, S. M. Apoio à Decisão: Metodologias para Estruturação de Problemas e Avaliação Multicritério de Alternativas. São Paulo: Insular, 2001.

ENSSLIN, L. et al. Avaliação do Desempenho de Empresas Terceirizadas com o uso da Metodologia Multicritério em Apoio à Decisão - Construtivista. Pesquisa Operacional, v. 30 , n. $125-152,2010$ a
ENSSLIN, L. et al. Identificação das Necessidades do Consumidor no Processo de Desenvolvimento de Produtos: Uma Proposta de Inovação llustrada para o Segmento Automotivo. Revista Produção, v. 21, n. 4, p. 555-569, 2010b. http://dx.doi.org/10.1590/S010365132011005000052

FERREIRA, M. P. et al. Management through performance indicators: results in a technological business incubator. Revista Produção, v. 18, p. 302-318, 2008.

FRANCO, L. A.; MONTIBELLER, G. Facilitated modelling in operational research. European Journal of Operational Research, v. 205, n. 3, p. 489-500, 2010. http://dx.doi. $\operatorname{org} / 10.1016 /$ j.ejor.2009.09.030

FUNDAÇÃo GETÚllo VARGAS. Pesquisas Econômicas. São Paulo, 2010. Disponivel em: <http:/www.portal.fgv.br>. Acesso em: 05 set. 2010.

GlL, A. C. Como elaborar projetos de pesquisa. São Paulo: Atlas, 1999.

GRZEBIELUCKAS, C. et al. Instrumento para identificação das necessidades do consumidor no processo de desenvolvimento do design: Um estudo ilustrado com o projeto de um automóvel. Gestão \& Produção, v. 18, n. 2, p. 337-350, 2011.

KEENEY, R. L.; RAIFFA, H. Decisions with Multiple Objectives: Preferences and Value Trade-offs. New York: Cambridge University Press, 1976.

KEENEY, R. L. Value Focused-Thinking: A Path to Creative Decision-making. Cambridge: Harvard University Press, 1992.

LACERDA, R. T. 0.; ENSSLIN, L.; ENSSLIN, S. R. A study case about a software project management success metrics. Skovde: Software Engineering Workshop (SEW)/ IEEE, 2009.

LACERDA, R. T. 0.; ENSSLIN, L.; ENSSLIN, S. R. A performance measurement framework in portfolio management: A constructivist case. Management Decision, v. 49, n. 4, p. 648-668, 2011a. http://dx.doi. org/10.1108/00251741111126530

LACERDA, R. T. 0.; ENSSLIN, L.; ENSSLIN, S. R. A performance measurement view of IT project management. International Journal of Productivity and Performance Management, v. 60, n. 2, p. 132-151, 2011b. http:// dx.doi.org/10.1108/17410401111101476

LANDRY, M. A note on the concept of problem. Quebec: Maurice Landry Faculty of Administrative Sciences, Laval University, 1995.

LANGENDYK, A. Estratégias de logística em uma empresa do setor automobilístico: o caso da Volkswagen-Audi no período 1996-2001. 2002. 192 f. Dissertação (Mestrado em Engenharia de Produção)-Universidade Federal de Santa Catarina, Florianópolis, 2002.

LIU, J.; DING, F-Y.; LALL, V. Using Data Envelopment Analysis to Compare Suppliers for Supplier Selection and Performance Improvement. Toronto: An International Journal, 2000.

LYRIO, M. V. L. et al. Construção de um Modelo de Avaliação de Desempenho da Secretaria de Desenvolvimento Regional da Grande Florianópolis: a Proposta da Metodologia Multicritério de Apoio à Decisão Construtivista. 5. ed. Florianópolis: Contextus, 2007.

MONTIBELLER, G. et al. Reasoning maps for decision aid: An integrated approach for problem-structuring and multi-criteria evaluation. Journal of the Operational 
Research Society, v. 59, n. 5, p. 575-589, 2008. http:// dx.doi.org/10.1057/palgrave.jors. 2602347

MONTIBELLER, G.; BELTON, V. Qualitative operators for reasoning maps: Evaluating multi-criteria options with networks of reasons. European Journal of Operational Research, v. 195, n. 3, p. 829-840, 2009. http://dx.doi. $\operatorname{org} / 10.1016 /$ j.ejor.2007.11.015

MONTIBELLER, G.; SHAW, D.; WESTCOMBE, M. Using decision support systems to facilitate the social process of knowledge management. Knowledge Management Research and Practice, v. 4, n. 2, p. 125-137, 2006. http://dx.doi.org/10.1057/palgrave.kmrp.8500092

RICHARDSON, R. J. Pesquisa Social: Métodos e Técnicas. 3. ed. São Paulo: Atlas, 2008.

ROY, B. Decision science or decision-aid science. European Journal of Operational Research, v. 66, p. 184-203, 1993. http://dx.doi.org/10.1016/0377-2217(93)90312-B

ROY, B. On operational research and decision aid. European Journal of Operational Research, v. 73, p. 23-26, 1994. http://dx.doi.org/10.1016/0377-2217(94)90136-8

ROY, B. The european school of MCDA: emergence, basic features and current works. Journal of Multi-Criteria Decision Analysis, v. 5, n. 1, p. 22-38, 1996. http:// dx.doi.org/10.1002/(SICl)1099-1360(199603)5:1\%3C22 :AID-MCDA93\%3E3.0.C0;2-F
ROY, B. Paradigms and Challenges, Multiple Criteria Decision Analysis - State of the Art Survey. International Series in Operations Research \& Management Science, v. 78, n. 1, p. 3-24, 2005.

ROY, B.; VANDERPOOTEN, D. The European School of MCDA: A Historical Review. Paris: Université Paris-Dauphin, 1995.

SKINNER, W. The productivity paradox. Management Review, v. 75, n. 9, p. 41-45, 1986.

TASCA, J. E. et al. An approach for selecting a theoretical framework for the evaluation of training programs. Journalof European Industrial Training, v. 34, n. 7, p. 631-655, 2010. http://dx.doi.org/10.1108/03090591011070761

TRINDADE, C. et al. Ferramentas da Qualidade: Aplicação na Atividade Florestal. 2. ed. Viçosa: Editora UFV, 2007.

VINCKE, P. L'Aide Multicritère À La Décision. Bruxelas: Éditions de l'Université de Bruxelles, 1989.

YIN, R. K. Estudo de Caso: planejamento e métodos. 3. ed. Porto Alegre: Bookman, 2005.

ZAMCOPÉ, F. C. et al. Modelo para avaliar o desempenho de operadores logísticos - Um estudo de caso na indústria têxtil. Gestão \& Produção, v. 17, n. 4, p. 693-705, 2010.

ZIMMERMANN, H. F. An application-oriented view of modeling uncertainty. European Journal of Operational Research, v. 122, n. 2, p. 190-198, 2000. http://dx.doi. org/10.1016/S0377-2217(99)00228-3

\section{Multi-criteria decision-aid constructivist model in the supplier evaluation process}

\section{Abstract}

This paper aims to evaluate mechanical equipment suppliers of an engineering organization in order to increase business competitiveness. To this end, a Multi-criteria Decision Aid - Constructivist (MCDA-C) methodology was used for addressing the following steps: i) Structuring; ii) Evaluation; iii) Recommendation. This has enabled the production of knowledge on the studied context, considering its important aspects, and the support in decisionmaking. The importance of this accomplishment is founded on the powerful tool left as a legacy to the involved parts (engineering organization and suppliers); the consequent improvements in the entire chain of Brazil's infrastructure; and the ennoblement of knowledge and the extrapolation of its theoretical-practical frontier in the Performance Evaluation area.

\section{Keywords}

Performance evaluation. Supplier evaluation. Multi-criteria decision aid constructivist methodology (MCDA-C). 